\title{
Aerodynamic Effects of Simulated Ice Accretion on a Generic Transport Model
}

Andy P. Broeren

Glenn Research Center, Cleveland, Ohio

Sam Lee

ASRC Aerospace Corporation, Cleveland, Ohio

Gautam H. Shah and Patrick C. Murphy

Langley Research Center, Hampton, Virginia 


\section{NASA STI Program . . . in Profile}

Since its founding, NASA has been dedicated to the advancement of aeronautics and space science. The NASA Scientific and Technical Information (STI) program plays a key part in helping NASA maintain this important role.

The NASA STI Program operates under the auspices of the Agency Chief Information Officer. It collects, organizes, provides for archiving, and disseminates NASA's STI. The NASA STI program provides access to the NASA Aeronautics and Space Database and its public interface, the NASA Technical Reports Server, thus providing one of the largest collections of aeronautical and space science STI in the world. Results are published in both non-NASA channels and by NASA in the NASA STI Report Series, which includes the following report types:

- TECHNICAL PUBLICATION. Reports of completed research or a major significant phase of research that present the results of NASA programs and include extensive data or theoretical analysis. Includes compilations of significant scientific and technical data and information deemed to be of continuing reference value. NASA counterpart of peer-reviewed formal professional papers but has less stringent limitations on manuscript length and extent of graphic presentations.

- TECHNICAL MEMORANDUM. Scientific and technical findings that are preliminary or of specialized interest, e.g., quick release reports, working papers, and bibliographies that contain minimal annotation. Does not contain extensive analysis.

- CONTRACTOR REPORT. Scientific and technical findings by NASA-sponsored contractors and grantees.
- CONFERENCE PUBLICATION. Collected papers from scientific and technical conferences, symposia, seminars, or other meetings sponsored or cosponsored by NASA.

- SPECIAL PUBLICATION. Scientific, technical, or historical information from NASA programs, projects, and missions, often concerned with subjects having substantial public interest.

- TECHNICAL TRANSLATION. Englishlanguage translations of foreign scientific and technical material pertinent to NASA's mission.

Specialized services also include creating custom thesauri, building customized databases, organizing and publishing research results.

For more information about the NASA STI program, see the following:

- Access the NASA STI program home page at http://www.sti.nasa.gov

- E-mail your question via the Internet to help@ sti.nasa.gov

- Fax your question to the NASA STI Help Desk at $443-757-5803$

- Telephone the NASA STI Help Desk at 443-757-5802

- Write to: NASA Center for AeroSpace Information (CASI) 7115 Standard Drive Hanover, MD 21076-1320 


\section{Aerodynamic Effects of Simulated Ice Accretion on a Generic Transport Model}

Andy P. Broeren

Glenn Research Center, Cleveland, Ohio

Sam Lee

ASRC Aerospace Corporation, Cleveland, Ohio

Gautam H. Shah and Patrick C. Murphy

Langley Research Center, Hampton, Virginia

Prepared for the

International Conference on Aircraft and Engine Icing and Ground Deicing sponsored by SAE International

Chicago, Illinois, June 13-17, 2011

National Aeronautics and

Space Administration

Glenn Research Center

Cleveland, Ohio 44135 


\section{Acknowledgments}

This research was supported by the NASA Aviation Safety Program. The authors thank Gene Addy and Colin Bidwell at the NASA Glenn Research Center for their important contributions in research planning and ice-accretion analysis. In addition, Sue Grafton, Earl Harris and Gary Wainwright at the NASA Langley Research Center are gratefully acknowledged for their efforts in the wind-tunnel model design, fabrication and aerodynamic testing.

Level of Review: This material has been technically reviewed by technical management.

Available from

NASA Center for Aerospace Information 7115 Standard Drive

Hanover, MD 21076-1320
National Technical Information Service 5301 Shawnee Road Alexandria, VA 22312

Available electronically at http://www.sti.nasa.gov 


\title{
Aerodynamic Effects of Simulated Ice Accretion on a Generic Transport Model
}

\author{
Andy P. Broeren \\ National Aeronautics and Space Administration \\ Glenn Research Center \\ Cleveland, Ohio 44135 \\ Sam Lee \\ ASRC Aerospace Corporation \\ Cleveland, Ohio, 44135 \\ Gautam H. Shah and Patrick C. Murphy \\ National Aeronautics and Space Administration \\ Langley Research Center \\ Hampton, Virginia 23681-2199
}

\begin{abstract}
An experimental research effort was begun to develop a database of airplane aerodynamic characteristics with simulated ice accretion over a large range of incidence and sideslip angles. Wind-tunnel testing was performed at the NASA Langley 12-ft Low-Speed Wind Tunnel using a 3.5 percent scale model of the NASA Langley Generic Transport Model. Aerodynamic data were acquired from a sixcomponent force and moment balance in static-model sweeps from $\alpha=-5^{\circ}$ to $85^{\circ}$ and $\beta=-45^{\circ}$ to $45^{\circ}$ at a Reynolds number of $0.24 \times 10^{6}$ and Mach number of 0.06 . The 3.5 percent scale GTM was tested in both the clean configuration and with fullspan artificial ice shapes attached to the leading edges of the wing, horizontal and vertical tail. Aerodynamic results for the clean airplane configuration compared favorably with similar experiments carried out on a 5.5 percent scale GTM. The addition of the large, glaze-horn type ice shapes did result in an increase in airplane drag coefficient but had little effect on the lift and pitching moment. The lateral-directional characteristics showed mixed results with a small effect of the ice shapes observed in some cases. The flow visualization images revealed the presence and evolution of a spanwise-running vortex on the wing that was the dominant feature of the flowfield for both clean and iced configurations. The lack of ice-induced performance and flowfield effects observed in this effort was likely due to Reynolds number effects for the clean configuration. Estimates of full-scale baseline performance were included in this analysis to illustrate the potential icing effects.
\end{abstract}

\section{Nomenclature}

$b \quad$ Wing span

c Local chord, streamwise direction

$c_{\text {mac }} \quad$ Mean aerodynamic chord

$C_{D} \quad$ Airplane drag coefficient, stability axis
$C_{l} \quad$ Airplane rolling moment coefficient, body axis, $0.25 c_{\text {mac }}$

$C_{L} \quad$ Airplane lift coefficient, stability axis

$C_{m} \quad$ Airplane pitching moment coefficient, stability axis, $0.25 c_{\text {mac }}$

$C_{n} \quad$ Airplane yawing moment coefficient, body axis, $0.25 c_{\text {mac }}$

$M \quad$ Mach Number

Re Reynolds number based upon mean aerodynamic chord

$S \quad$ Wing reference area

$x \quad$ Airfoil section coordinate in chordwise direction, $x=0$ at section leading edge

$y \quad$ Spanwise location on airplane, $y=0$ corresponds to plane of symmetry

$z \quad$ Airfoil section coordinate in normal direction, $z=0$ at section leading edge

$\alpha \quad$ Angle of attack or incidence angle

$\beta \quad$ Angle of sideslip or yaw angle

CFD Computational fluid dynamics

GTM Generic Transport Model

IPS Ice-protection system

IRAC Integrated Resilient Aircraft Control

LWC Liquid Water Content

MVD Median Volumetric Diameter

\section{Introduction}

The Integrated Resilient Aircraft Control (IRAC) Project of the NASA Aviation Safety Program has sought to develop aircraft control design tools and techniques for enabling safe flight in the presence of adverse conditions. These adverse conditions, such as those caused by environmental factors, sensor faults or airframe damage, include upsets leading to aircraft loss-of-control situations (Ref. 1). Airframe ice accretion has been identified in a number of studies as a causal factor leading to loss of control. Reehorst et al. (Ref. 2) 
reviewed icing-related accidents as identified in a recent report on aircraft loss of control. Ratvasky and Lee (Ref. 3) also identified the potential for aircraft loss of control resulting from ice accretion. This provided motivation for the consideration of icing effects for development of advanced modeling and simulation toward flight safety improvement under the auspices of the IRAC project. The advanced flight simulation models are being developed for high angle of attack and sideslip conditions. There is a lack of steady and unsteady aerodynamic data for airplanes operating at extreme conditions consistent with the loss-of-control accident database. These data are useful for the development of high-fidelity flight simulators at high $\alpha$ and $\beta$ for upset recovery training, accident reconstruction and validation of advanced flight control (Ref. 4).

A closely related effort has been carried out for a commercial transport category airplane configuration subjected to simulated airframe damage conditions. Shah et al. (Refs. 5 and 6) compiled an extensive database of static and dynamic aerodynamic characteristics for the NASA Langley Generic Transport Model (GTM) with and without simulated damage. The GTM was designed to represent a large, commercial, twin-engine, transport-category airplane and was developed as a platform for flight dynamics modeling and simulation. Static and dynamic wind-tunnel tests of a 5.5 percent scale model were performed over a large range of incidence and sideslip at the NASA Langley 14- by 22-ft wind tunnel at a Reynolds number based on mean aerodynamic chord of $0.54 \times 10^{6}$. Airframe damage was simulated by systematically removing portions of the wing and tailplane in addition to other scenarios. Shah (Ref. 6) documented the changes in the airplane stability and control characteristics and noted the potential modeling challenges associated with the asymmetries and nonlinearities for the simulated damage configurations.

The static and dynamic, pre- and post-stall aerodynamics of the GTM configuration have been investigated using a variety of experimental capabilities. This has included the NASA Langley 14- by 22-ft wind tunnel described above with conventional static testing capabilities and a forced-oscillation system for dynamic testing. Dynamic experiments on a 3.5 percent scale GTM have also been conducted at the NASA Langley Vertical Spin Tunnel using its rotary balance rig. In addition to these ground-based facilities, NASA Langley has also developed a 5.5 percent scale remotely piloted flying testbed that is dynamically scaled and designed to be flown into and recover from extreme upset flight conditions (Ref. 4) Data from these sources can be subsequently combined to model the airplane behavior for flight simulation and control research (Ref. 7). However, as noted by Foster et al. (Ref. 4) and Owens et al., (Ref. 8). significant challenges remain in scaling the subscale, low-Reynolds number data into the flight scale and Reynolds number regime. While flight testing of the actual airplane does provide full-scale, flight-Reynolds number data, it remains cost prohibitive, and is unsafe in high $\alpha$ and $\beta$ conditions. Another increasingly important tool in the modeling effort is computational fluid dynamics (CFD). Frink et al. (Ref. 9) have demonstrated the potential capabilities of CFD in providing useful flight dynamics information using the subscale, low-Reynolds number experimental database for validation. The authors have noted that the CFD methods may be applied with more certainty at higher-Reynolds number flight conditions, thus providing another path for estimating full-scale vehicle response.

Analogous research programs have also been carried out in order to investigate the effects of ice accretion on flight dynamics and develop flight training simulation devices. Ratvasky et al. (Ref. 10) describe the development of a piloted flight simulator for icing effects training or Ice Contamination Effects Flight Training Device (ICEFTD). The ICEFTD was based upon the modified DeHavilland DHC-6 Twin Otter airplane used for icing flight research at NASA Glenn. This development program was a comprehensive effort that included icing aerodynamics, geometry and Reynolds number scaling studies, static and dynamic wind-tunnel testing and flight validation for both the baseline airplane configuration and with a series of artificial ice shapes (Refs. 11 and 12). The ICEFTD was subsequently used in a variety of settings for pilot evaluation and training (Ref. 13). More recent research conducted with the ICEFTD has been used to develop a knowledge-based, envelope-protection system that provides cues to the pilot for maintaining safe flight in simulated icing conditions (Refs. 14 and 16).

The twin-engine turboprop ICEFTD development served as a model for a follow-on program with a twin-engine business jet airplane. As before, a series of geometry and Reynolds number scaling studies were performed with various models of the semi-span wing panel including the aileron. This provided scaling information for static and dynamic data on a subscale, complete-airplane model. The scaled data were subsequently used to build the icing effects training simulator (Refs. 17 and 18). Finally, a modest flight validation program was performed using artificial ice shapes attached to the airplane (Ref. 19). All of this research was carried out for the baseline (clean) configuration and with three iced configurations based upon ice-protection system (IPS) pre-activation roughness, failed IPS and runback ice shapes. The combined results showed that high-fidelity flight simulation for icing effects can be performed, provided the necessary scaling and validation has been accomplished.

The lessons learned from these research programs and others are summarized in a recent review of icing effects simulation and modeling. Ratvasky et al. (Ref. 20) build on the foundations of two-dimensional experiments that clearly show traditional icing effects such as maximum lift degradation and increased drag, to changes in control surface effectiveness, hinge moment reversals and reduced pitch damping derived from dynamic three-dimensional model experiments. Ratvasky et al. (Ref. 20) reviewed the current state of icing effects modeling and discuss the need for this work to continue on to other platforms. For example, the past efforts involving the twin-engine turboprop and business jet cannot be applied across the entire spectrum of airplanes. More 
research is required for other classes including regional jets, large transports and future designs such as the Blended-WingBody.

The overall goal of the current work is to extend the aforementioned modeling and simulation efforts to an iced-GTM configuration. The specific objective of the research described in this paper was to obtain the subscale, low-Reynolds number wind-tunnel data that can be used for preliminary model comparisons and CFD validation. As noted above, developing a high-fidelity flight simulation model requires the synthesis of many research efforts. The work presented here represents the initial stages of the overall effort. In order to accomplish the specific objectives, a 3.5 percent scale GTM was tested at the NASA Langley 12-ft Low-Speed Wind Tunnel in both the clean and iced configuration. Artificial ice shapes were designed and built based upon computational analysis. Aerodynamic data were acquired over a large range of angle of attack and sideslip at a Reynolds number of $0.24 \times 10^{6}$. Surface-oil flow visualization was also performed for selected static cases to provide qualitative flowfield information. These results are presented and discussed in the context of past work where appropriate.

\section{Experimental Methods}

The experiments were carried out at the NASA Langley 12-ft Low-Speed Wind Tunnel. This atmospheric facility is comprised of a regular octagonal test section measuring $12-\mathrm{ft}$ between the parallel surfaces and approximately $20-\mathrm{ft}$ long. Originally designed for free-flight simulation testing (see http://gis.larc.nasa.gov/historic/12-Foot_Low_Speed_Tunnel), the tunnel has truncated inlet and diffuser sections as shown in Figure 1. The wind tunnel is driven by a fan capable of generating test-section dynamic pressure up to 7 psf. Most of the testing was conducted at a dynamic pressure of $5 \mathrm{psf}$ corresponding to a Reynolds number based upon mean aerodynamic chord of approximately $0.24 \times 10^{6}$ and a Mach number of approximately 0.06 . A small number of trials were performed at lower Reynolds and Mach number. The data acquisition and tunnel control software were programmed to maintain the desired value of dynamic pressure as the model was positioned through the various $\alpha$ and $\beta$ sweeps. The static aerodynamic data were acquired from a six-component balance located inside the model. As shown in Figure 2, the model was sting mounted to a C-sector positioning system for the static tests. The 3.5 percent scale GTM was designed based upon the 5.5 percent scale model used in numerous tests at the Langley 14- by 22-ft wind tunnel (Refs. 5 and 6). The model was constructed in sections using fused deposition modeling, a rapid-prototyping method. The pieces were then fitted together to form the completed model. The model was sanded smooth and painted flat black. Important geometry information for the 3.5 percent scale GTM is listed in Table I.

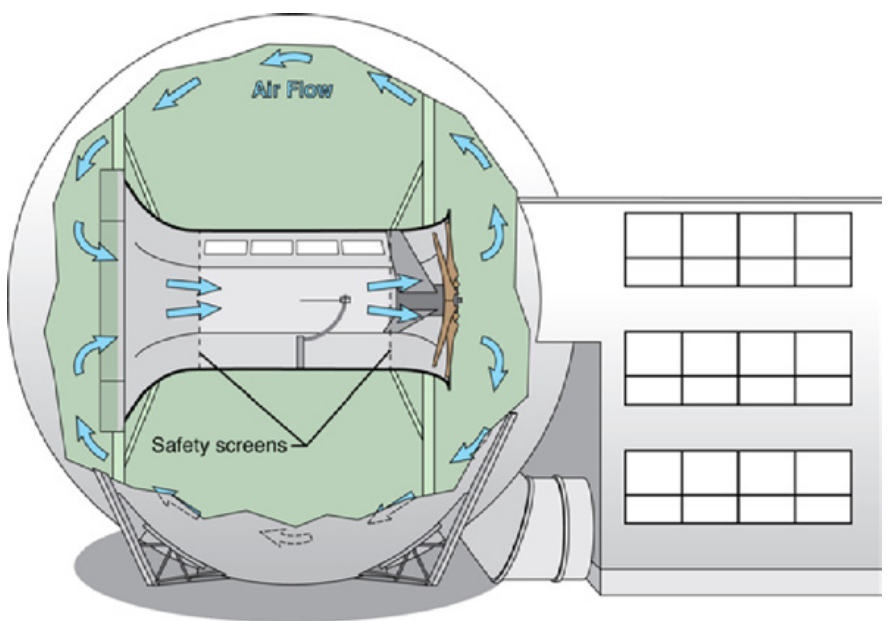

Figure 1.-Cutaway schematic of NASA Langley 12-ft LowSpeed Wind Tunnel.

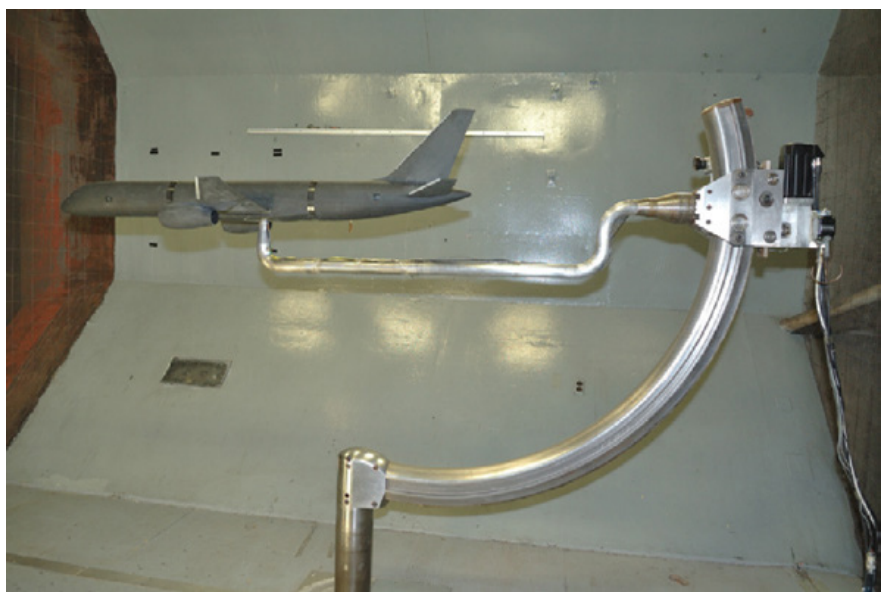

Figure 2.-3.5 percent Scale GTM installed in the NASA Langley 12-ft Low-Speed Wind Tunnel C-sector mounting and positioning system.

TABLE I.-1 GEOMETRY INFORMATION FOR THE 3.5 PERCENT SCALE GTM

\begin{tabular}{|c|}
\hline Dimension \\
\hline Wing span, $b$.. \\
\hline Wing reference area, $S$... \\
\hline Mean aerodynamic chord, $c_{m a c} \ldots . .$. \\
\hline Wing root chord \\
\hline Wing tip chord.... \\
\hline Wing aspect ratio. \\
\hline Wing taper ratio ........ \\
\hline$\ldots . . .25^{\circ}$ \\
\hline Fuselage length... \\
\hline Horizontal tail span... \\
\hline 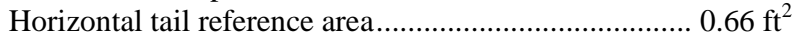 \\
\hline 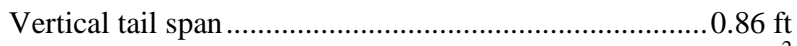 \\
\hline Vertical tail reference area ........................ \\
\hline
\end{tabular}


The static aerodynamic data sweeps were performed over a $90^{\circ}$ angle of attack range $\left(\alpha=-5^{\circ}\right.$ to $\left.85^{\circ}\right)$ and a $90^{\circ}$ angle of sideslip range $\left(\beta=-45^{\circ}\right.$ to $\left.45^{\circ}\right)$. Data were acquired from the force balance at discrete, pre-set values of angle of attack and sideslip. These data were filtered at $10 \mathrm{~Hz}$ and 500 samples per channel were averaged over a 10-sec interval. The force and moment coefficients were calculated from the balance loads and tunnel calibration data for dynamic pressure. The balance moment center was located at $0.25 c_{\text {mac }}$ so no moment transfers were performed. The tunnel calibration results in a ratio of dynamic pressure measured at the upstream pitot to one measured at the model location. This was the only correction applied to the dynamic pressure. Further tunnel qualification tests with calibration models having similar frontal area to the 3.5 percent scale GTM at low to moderate angle of attack yielded good agreement in known performance data without additional blockage corrections.

The experimental uncertainty in the performance coefficients was estimated using the methods of Kline and McClintock (Ref. 21) and Coleman and Steele (Ref. 22) for 20:1 odds. The values listed in Table II were calculated for the clean-model configuration at $R e=0.24 \times 10^{6}, M=0.06$ and $\alpha=\beta=8^{\circ}$. These uncertainties take in account uncertainty in the forces and moments determined from the balance calibration and the uncertainty in the dynamic-pressure measurement. They do not include potential uncertainties in the model reference area, mean aerodynamic chord and wing span as these were assumed to be negligibly small. All of these uncertainties were acceptable for the purposes of this investigation. In addition to this analysis, several repeat runs were performed for both clean and iced configurations and these run-to-run variations in the coefficients were much smaller than these uncertainties listed in Table II.

TABLE II.-ESTIMATED EXPERIMENTAL UNCERTAINTIES IN AERODYNAMIC DATA FOR 3.5 PERCENT SCALE CLEAN GTM AT $\alpha=8^{\circ}$ AND $\beta=8^{\circ}$ IN NASA LANGLEY 12-ft LOW-SPEED WIND TUNNEL

\begin{tabular}{|c|c|c|c|}
\hline $\begin{array}{c}\text { Aerodynamic } \\
\text { quantity }\end{array}$ & $\begin{array}{c}\text { Reference } \\
\text { value }\end{array}$ & $\begin{array}{c}\text { Absolute } \\
\text { uncertainty }\end{array}$ & $\begin{array}{c}\text { Relative } \\
\text { uncertainty }\end{array}$ \\
\hline$C_{L}$ & 0.7387 & \pm 0.0068 & $\pm 0.92 \%$ \\
$C_{D}$ & 0.0632 & \pm 0.0030 & $\pm 4.83 \%$ \\
$C_{m}$ & -0.1431 & \pm 0.0023 & $\pm 1.62 \%$ \\
$C_{l}$ & -0.0252 & \pm 0.0003 & $\pm 1.03 \%$ \\
$C_{n}$ & 0.0315 & \pm 0.0006 & $\pm 1.93 \%$ \\
\hline
\end{tabular}

Surface-oil flow visualization was performed on the left and right wings for selected static angles of attack and sideslip based upon the force and moment data. The wings were first covered with self-adhesive Ultracote Plus surface covering. This covering material provided an exceptionally smooth surface for the oil to flow. A base coat of SAE 30 weight motor oil was applied to the surface covering. Any excess was wiped clean prior to the application of a mixture of baby oil and UV fluorescent dye. The oil-dye mixture was applied with a small sponge roller used for trim painting applications. UV blacklights were used to illuminate the test surface. The appropriate angle of attack and sideslip were set and the airflow was set to a dynamic pressure of 5 psf for approximately $10 \mathrm{~min}$. The oil flow was monitored via video camera during the run and recorded on $8 \mathrm{~mm}$ tape. Thus, ambiguities were avoided by watching the development of the oil patterns during the runs. Run times of 10 min were sufficiently long for steady state conditions to develop in the oil patterns. At the conclusion of the run, the fan was shut down and the tunnel was entered to take photographs with a digital camera. Usually the oil-dye mixture could be redistributed for the next run using the sponge roller. After about four runs, it was necessary to wipe off the oil-dye mixture and apply a fresh coating.

\section{Artificial Ice Shapes}

It was determined at the beginning stages of this program that large, glaze-horn type ice accretion (with the iceprotection system not activated) should be used for aerodynamic testing on the 3.5 percent scale GTM. This was primarily due to the practical limitations of the 3.5 percent model scale. Because of the small model size relative to full scale, smaller ice shapes would have been impractical to fabricate and install accurately. Also, previous research has shown that geometric scaling is appropriate for large, leadingedge ice accretion. For example, Lee et al. (Ref. 17) tested various artificial ice shapes on a full-scale and corresponding 8.3 percent scale semi-span business jet wing over a Reynolds number range of $0.15 \times 0^{6}$ to $4.2 \times 10^{6}$. They found little variation in the iced-model performance over this range with the large, leading-edge ice shape. Since time and resources did not allow for a suitable geometry and Reynolds number scaling study on a wing or tail surface component, a large ice shape was selected since it required neither.

The artificial ice shapes tested on the 3.5 percent GTM were developed through a series of computational analysis efforts. A flowfield solution on the full-scale airplane was obtained using the USM3D code for an approximate hold condition at an aircraft angle of attack of $6^{\circ}$ at $M=0.33$ and $R e=17 \times 10^{6}$. Local flow characteristics taken from the flowfield solution were used to analyze selected wing section cuts using LEWICE (Ref. 23), the NASA two-dimensional ice growth software. This process was used to rapidly survey a large variety of potential icing-cloud conditions to produce a large glaze-horn ice shape. The selected conditions were: total temperature $=27^{\circ} \mathrm{F}$, a droplet MVD $=20 \mu \mathrm{m}$, a cloud LWC $=$ $0.5 \mathrm{~g} / \mathrm{m}^{3}$ for a $45-\mathrm{min}$ exposure. These conditions along with the flowfield solution were used as inputs to LEWICE3D (Ref. 24) to generate ice accretion on the entire wing and horizontal and vertical tail.

LEWICE3D generated ice accretion in a series of twodimensional spanwise section cuts. These were lofted into a quasi-three-dimensional geometry along the span of the wing and tail surfaces. Cross-sections of the ice shapes at various spanwise locations on the wing are shown in Figure 3. These cross-sections were taken in the streamwise direction and normalized by the corresponding local chord. So the large 

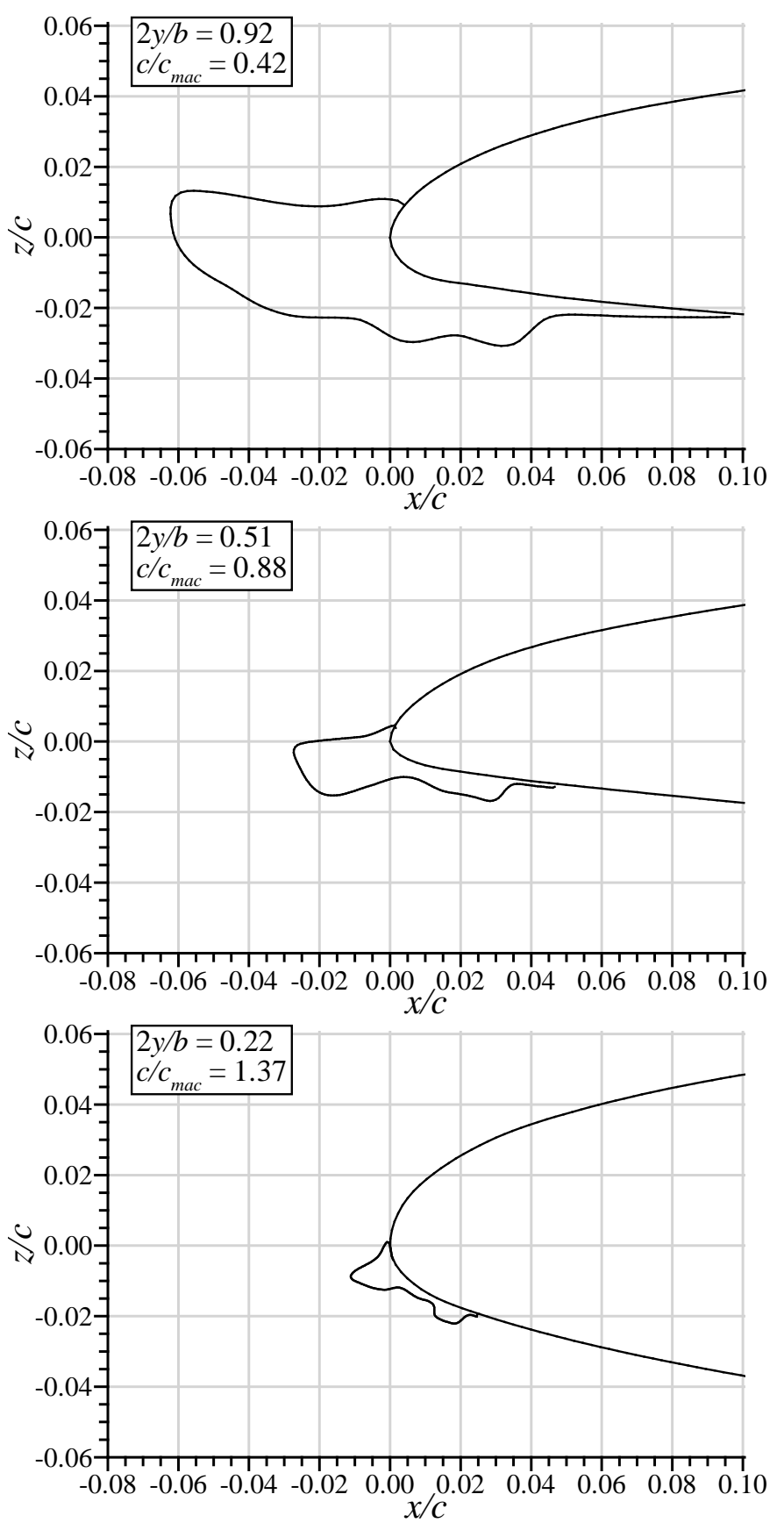

Figure 3.-Cross-section view of wing ice shape at three spanwise locations on the 3.5 percent scale GTM.

horn-shape near the wing tip $(2 y / b=0.92)$ was over 6 percent of the local chord in length. This corresponds to a length of 0.18 in. on the 3.5 percent scale GTM and 5.0 in. at full scale. The other spanwise locations shown in Figure 3 are near midspan $(2 y / b=0.51)$ and approximately halfway between the fuselage and the engine pylon $(2 y / b=0.22)$. These cross sections show that the glaze ice shape becomes smaller at locations farther inboard. This is explained by the smaller total
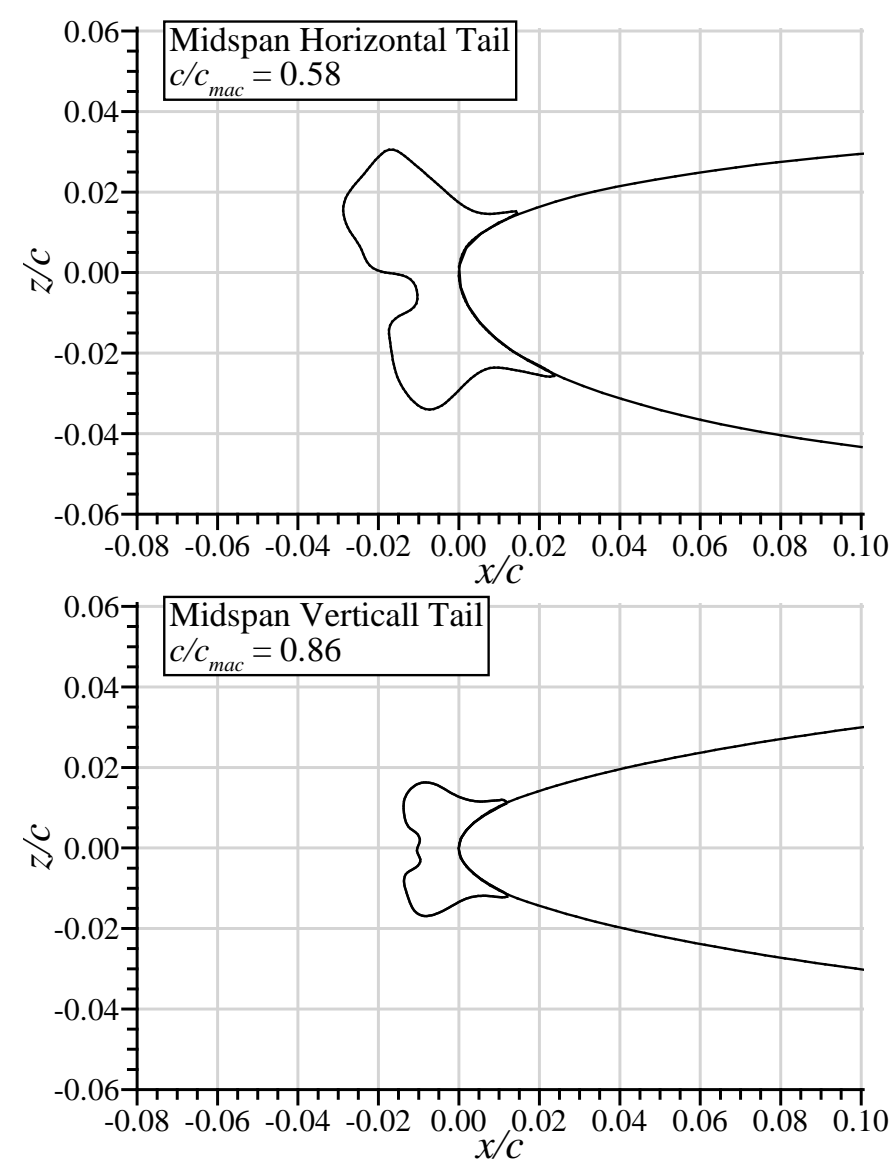

Figure 4.-Cross-section view of horizontal and vertical ice shapes on the 3.5 percent scale GTM.

collection efficiencies associated with the larger physical dimension of the leading-edge geometry moving inboard on the wing. The ice shapes also tend to angle downward from the midspan station inboard because of the increased sectional lift values moving inboard on the wing. The ice-shape cross sections for the horizontal and vertical tail are shown in Figure 4 for the midspan stations of each surface. For these figures the local chord length was also normalized by the wing mean aerodynamic chord length. The ice shape on the vertical tail was nearly symmetric since there was no net lift on this surface. The cross-sections shown in Figure 3 and Figure 4 are fairly smooth. This smoothing resulted from the lofting process that was used to develop the fully three-dimensional shapes from the LEWICE3D cross-sections. These threedimensional shapes were manufactured using the fused deposition modeling technique and were fixed to the leading edges using a combination of alignment pins and tape as shown in Figure 5. No roughness was applied to the smooth shapes. Note that there was no ice shape on the wing behind the engines. This occurred because the engine prevented droplet impingement in this region, sometimes referred to as a "shadow zone." This was the only iced-airplane configuration tested in this effort. 

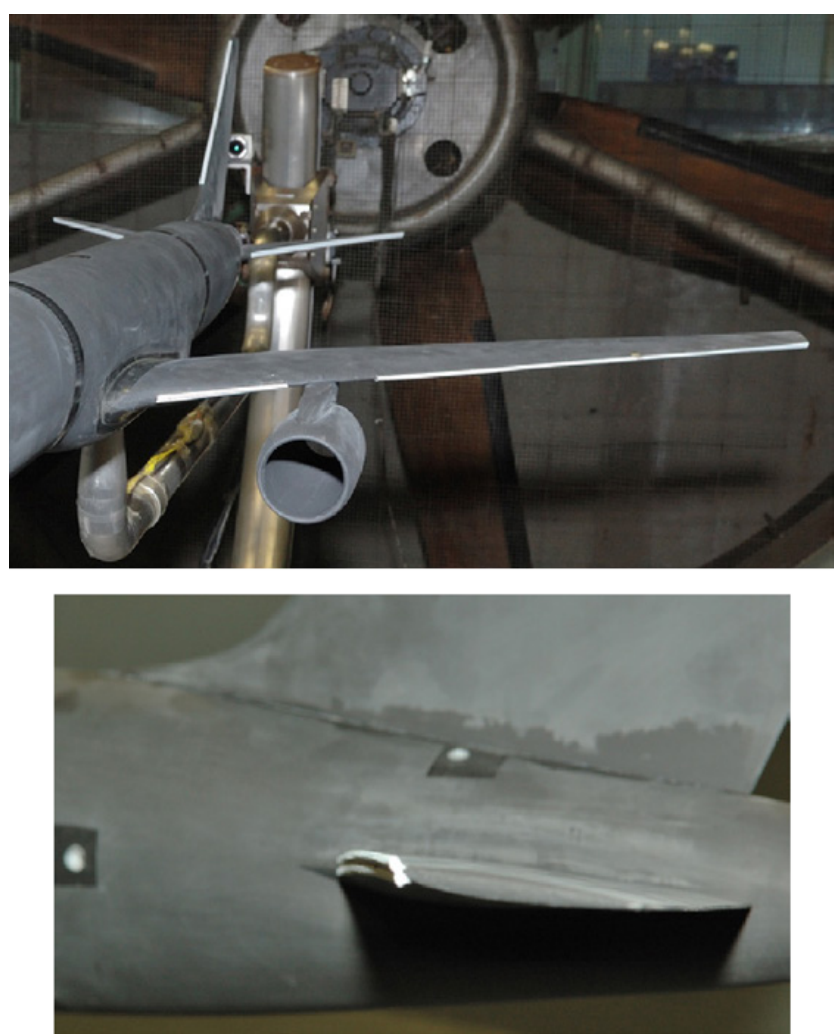

Figure 5.-Artificial ice shapes installed on the 3.5 percent scale GTM, top-wing and tail leading edges; bottomhorizontal tail.

\section{Results and Discussion}

\section{Clean Model}

The static aerodynamic measurements were carried out for a large range of incidence and yaw angles to document the clean performance of the baseline 3.5 percent scale GTM. These data were compared to previous results for the 5.5 percent scale GTM that was tested in the NASA Langley 14- by 22-ft wind tunnel (Ref. 5). The 5.5 percent scale GTM data were for the clean configuration with boundary-layer trip strips applied to the upper and lower surfaces of the wing and tail (Ref. 5) while the clean-model data for the 3.5 percent scale GTM had no boundary-layer trip strips. A comparison of airplane lift, drag and pitching-moment coefficients is plotted in Figure 6 for $\beta=0^{\circ}$. In absolute terms, the lift-curve and pitchingmoment slopes for the 5.5 percent scale model were slightly lower than for the 3.5 percent scale model in the curves leading up to stall. This could be explained by the lack of blockage correction in the present data. However, the drag data would be similarly affected, while the data in Figure 6 match very well in the pre-stall region. This agreement in drag also suggests minimal effect of the boundary-layer trips applied to the 5.5 percent scale model. The differences in pitching moment may also be due to a small offset in the moment center or horizontal tail incidence between the two
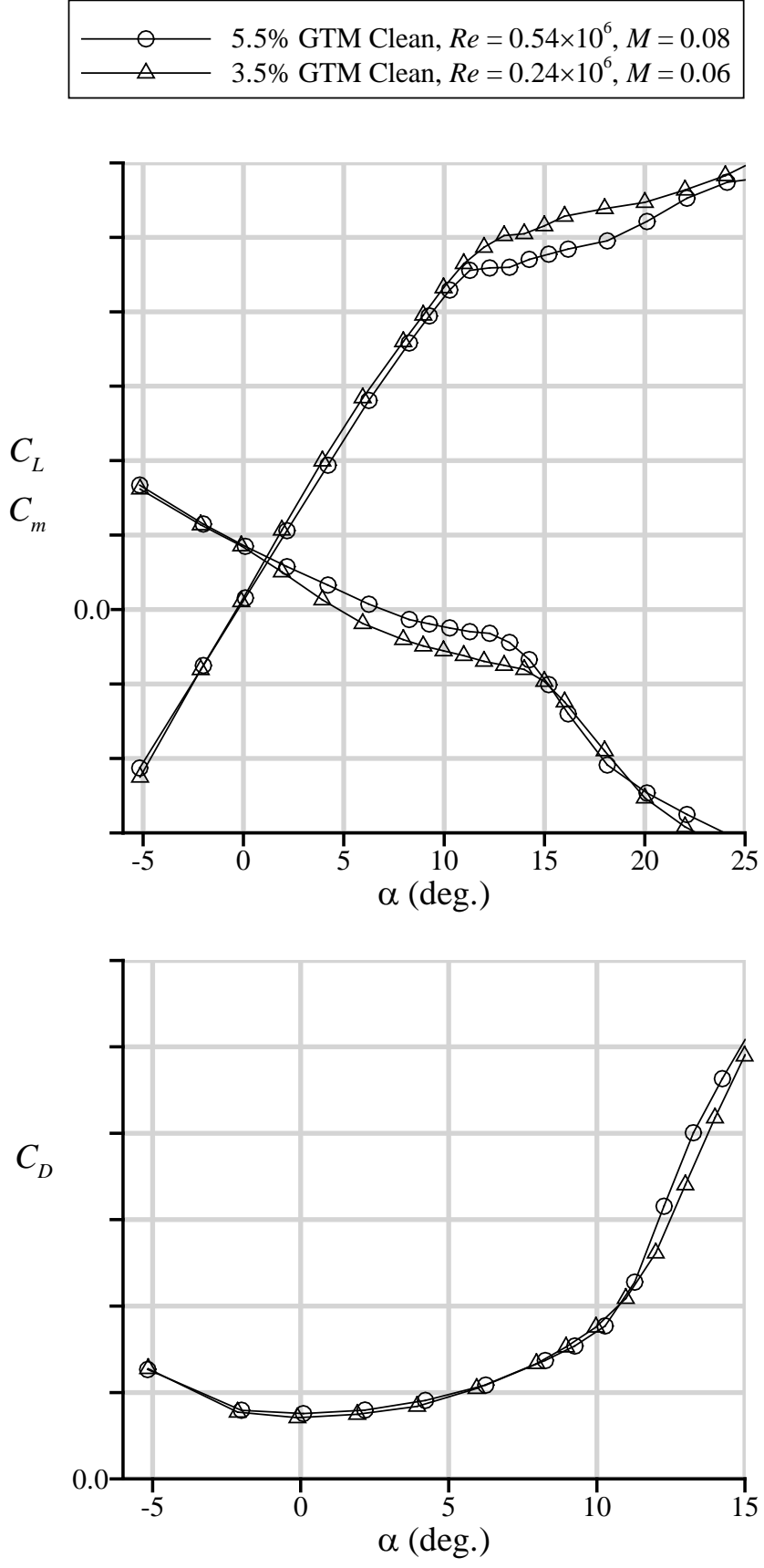

Figure 6.-Comparison of baseline (clean) GTM longitudinal characteristics at $\beta=0^{\circ} ; 5.5$ percent GTM data after Shah et al. (Ref. 5).

models. At $\alpha \approx 11^{\circ}$, there was a clear stall break in lift coefficient for the 5.5 percent scale GTM, accompanied by a large change in pitching-moment slope for $\alpha>14^{\circ}$. Stall for the 3.5 percent scale model was not as well defined, but occurred at an angle of attack that was at least $2^{\circ}$ or $3^{\circ}$ higher, corresponding to the break in the pitching-moment curve. This is consistent with the drag coefficient that was lower for the 3.5 percent scale model for incidence angles greater than $11^{\circ}$. 

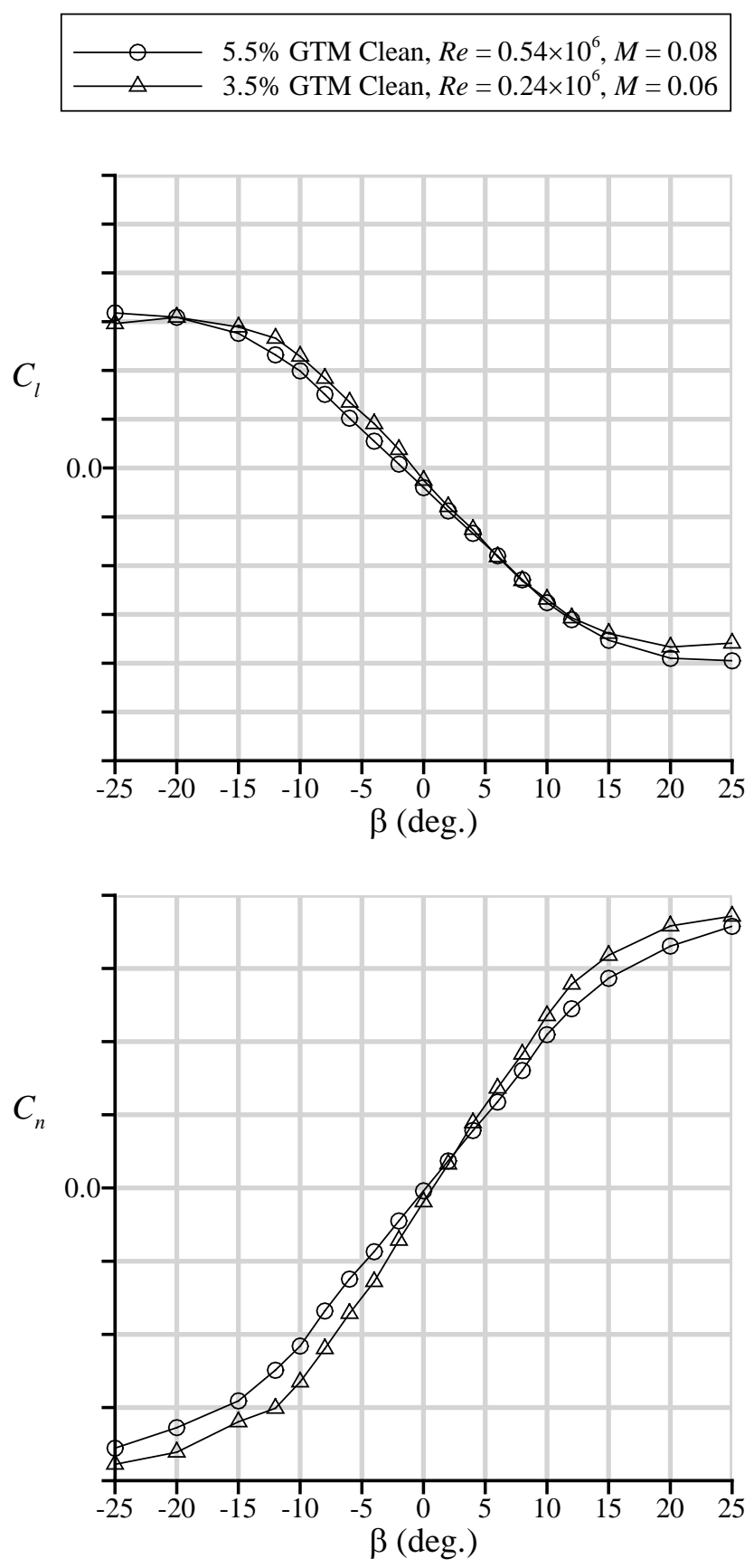

Figure 7.-Comparison of baseline (clean) GTM lateraldirectional characteristics at $\alpha=0^{\circ} ; 5.5$ percent GTM data after Shah et al. (Ref. 5).

For this $\beta=0^{\circ}$ condition, similar agreement between the data sets was observed in the roll and yaw axes. Of course, there was very little variation with angle of attack due to the model symmetry.

Further comparison of the baseline data in roll and yaw is shown in Figure 7 for a sideslip angle sweep at $\alpha=0^{\circ}$. The data show the large variation in these coefficients and change in sign with sideslip as expected for the lateral-directional

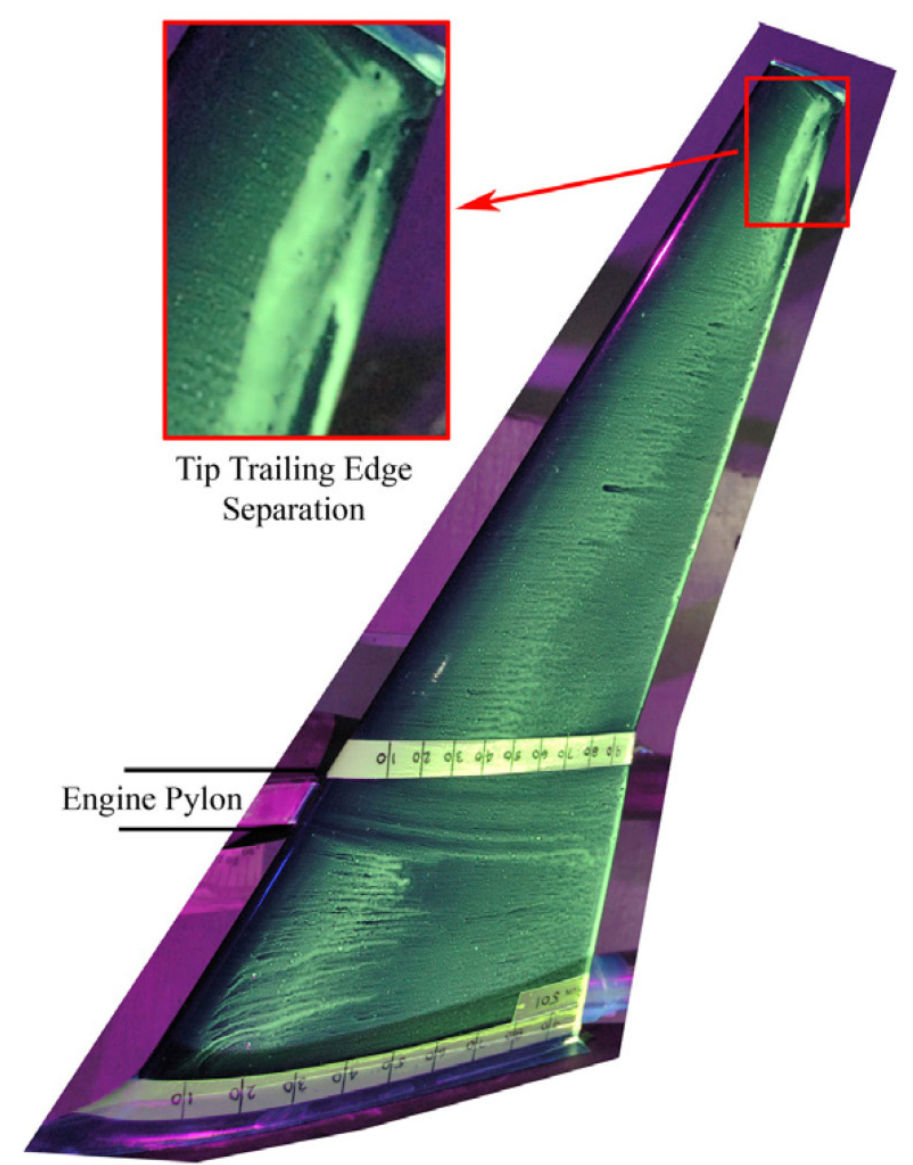

Figure 8.- Surface-oil flow visualization on the clean right wing for $\alpha=4^{\circ}$ and $\beta=0^{\circ}$ Flow is from left to right.

characteristics. The agreement in rolling-moment coefficient between the two data sets is fairly good over the range shown. It is unclear as to why there are larger differences for yawing moment. In both cases the absolute slope is again lower for the 5.5 percent scale model which could have resulted from potential uncorrected blockage effects on the 3.5 percent scale model. Similar comparisons were observed for the numerous incidence and sideslip angle sweeps performed. Shah et al. (Ref. 5) documented the variation in longitudinal and lateral characteristics for the 5.5 percent scale GTM over a large $\alpha$ and $\beta$-range. These plots are not reproduced here because similar results were observed for the present series of tests.

Surface-oil flow visualization was performed on the baseline configuration for $\alpha=4^{\circ}, 8^{\circ}, 10^{\circ}, 12^{\circ}$ and $14^{\circ}$ documenting the time-averaged surface flowfield on the wings leading up to stall for $\beta=0^{\circ}$. A flow visualization image of the right wing is shown in Figure 8 at $\alpha=4^{\circ}$. At this angle of attack, the surface flow was fairly uniform in the streamwise direction everywhere on the wing, except near the trailing-edge tip region. In this location, oil accumulated and appeared to flow upstream right at the trailing edge of the wing tip; thus indicating local boundary-layer separation as indicated in the figure. 


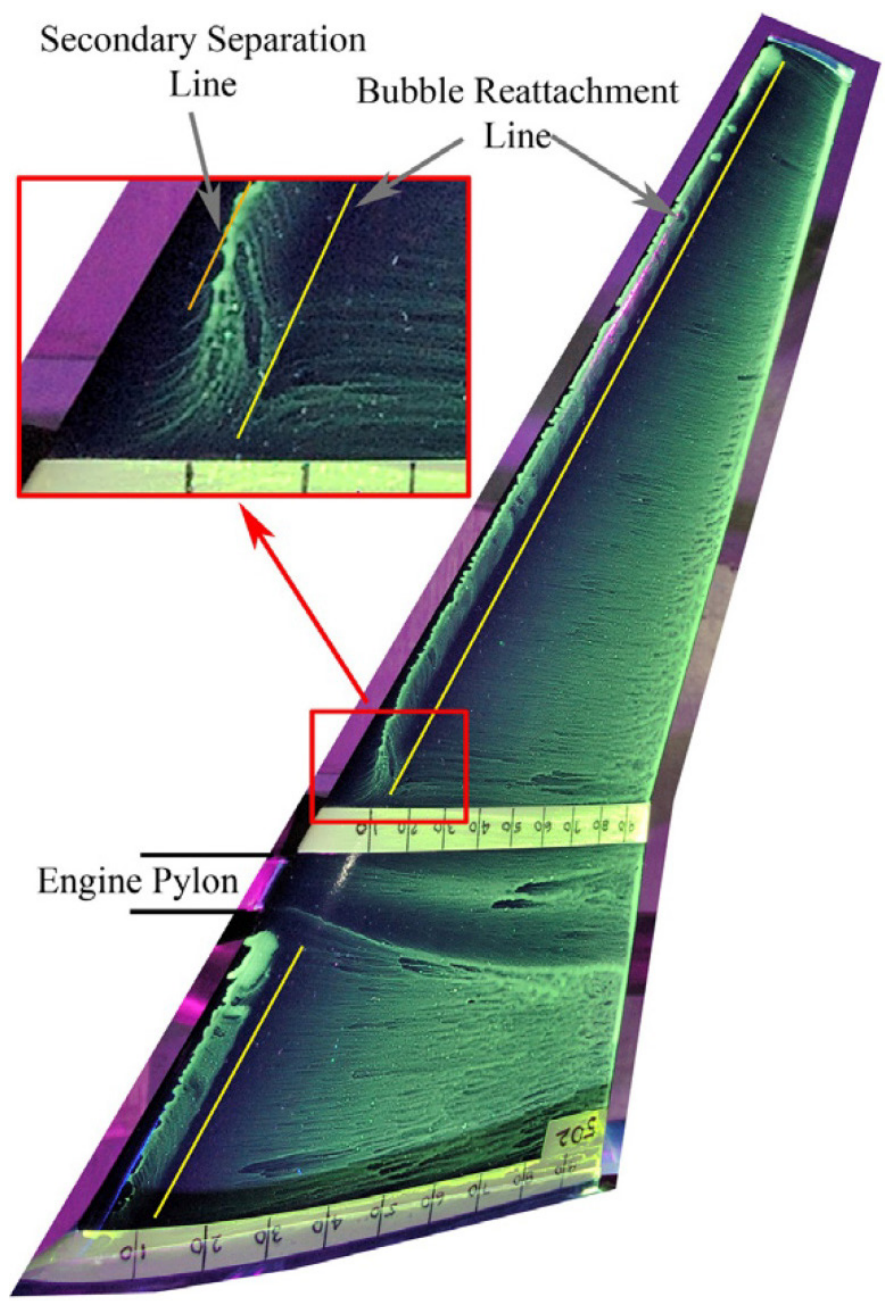

Figure 9.-Surface-oil flow visualization on the clean right wing for $\alpha=8^{\circ}$ and $\beta=0^{\circ}$ Flow is from left to right.

Increasing the angle of attack to $8^{\circ}$ led to the formation of a spanwise-running vortex centered along the leading-edge separation bubble reattachment location illustrated in Figure 9. This complex flowfield is also described with the aid of Figure 10 which is a schematic representation adapted from Poll (Ref. 25). Poll refers to the leading-edge separation location as the "primary" separation (c.f., Figure 10) that led to a vortex sheet rolling up to form a strong vortex very close to the wing surface. This vortex drew free-stream fluid down to the surface along the reattachment line indicated in Figure 9 and Figure 10. This formed a closed, leading-edge separation bubble with surface flow moving upstream between the reattachment location and the leading edge. Poll's model suggests that initially this reverse flow experiences a favorable pressure gradient, but then moves into a region of adverse pressure gradient leading to the "secondary" separation of the reversed flow. This is indicated in Figure 10 and can be seen in Figure 9 as the line of oil accumulation upstream of and approximately parallel to the reattachment line. Downstream of the reattachment location, the surface flow was uniform and
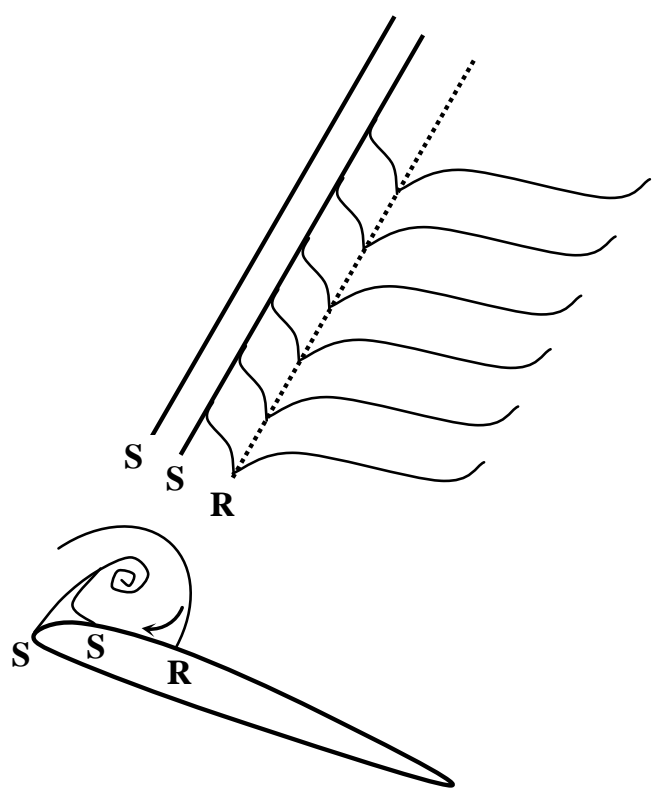

$$
\begin{aligned}
& \mathrm{S}=\text { Separation } \\
& \mathrm{R}=\text { Reattachment }
\end{aligned}
$$

Figure 10.-Fundamental representation of flowfield features observed in Figure 9. Adapted from Poll (Ref. 25).

generally in the streamwise direction to the wing trailing edge. The apparent separation near the wing tip that was observed at $\alpha=4^{\circ}$, was not observed at $\alpha=8^{\circ}$, perhaps due to the influence of the spanwise vortex. Finally, Figure 9 shows an increased effect of the engine nacelle and pylon that formed a distinct "wake" in the surface flow as well as an increased effect of the wing-fuselage juncture flow.

Increasing the angle of attack to $10^{\circ}$ resulted in no significant changes to the surface-flow topology. The only noteworthy difference from $\alpha=8^{\circ}$ was that the reattachment location of the spanwise vortex appeared to have moved closer to the leading edge, while the secondary separation location remained in approximately the same location. Thus indicating a slight decrease in the size of the leading-edge separation bubble. Continuing to $\alpha=12^{\circ}$ brought significant changes to the surface flow as was expected based upon the impending stall break in the lift curve (c.f. Figure 6). The flow visualization in Figure 11 indicates that the spanwise vortex had broken down in to two separate structures. There appears to be a small spanwise-running vortex from the fuselage-junction region forming a partial-span separation bubble. This structure apparently interacted with flow emanating from the inboard side of the engine-nacelle pylon/wing junction. Then on the outboard side of the pylon another partial-span vortex appeared to have formed. Unlike at lower angles of attack, the vortex in this case appears to have lifted off the surface in a downstream direction near the wing midspan section. From the midspan section inboard to the root, the surface flow is generally in the streamwise direction to the trailing edge, indicating significant loading on this inboard half of the wing. Meanwhile on the outboard portion of the wing, on the other 


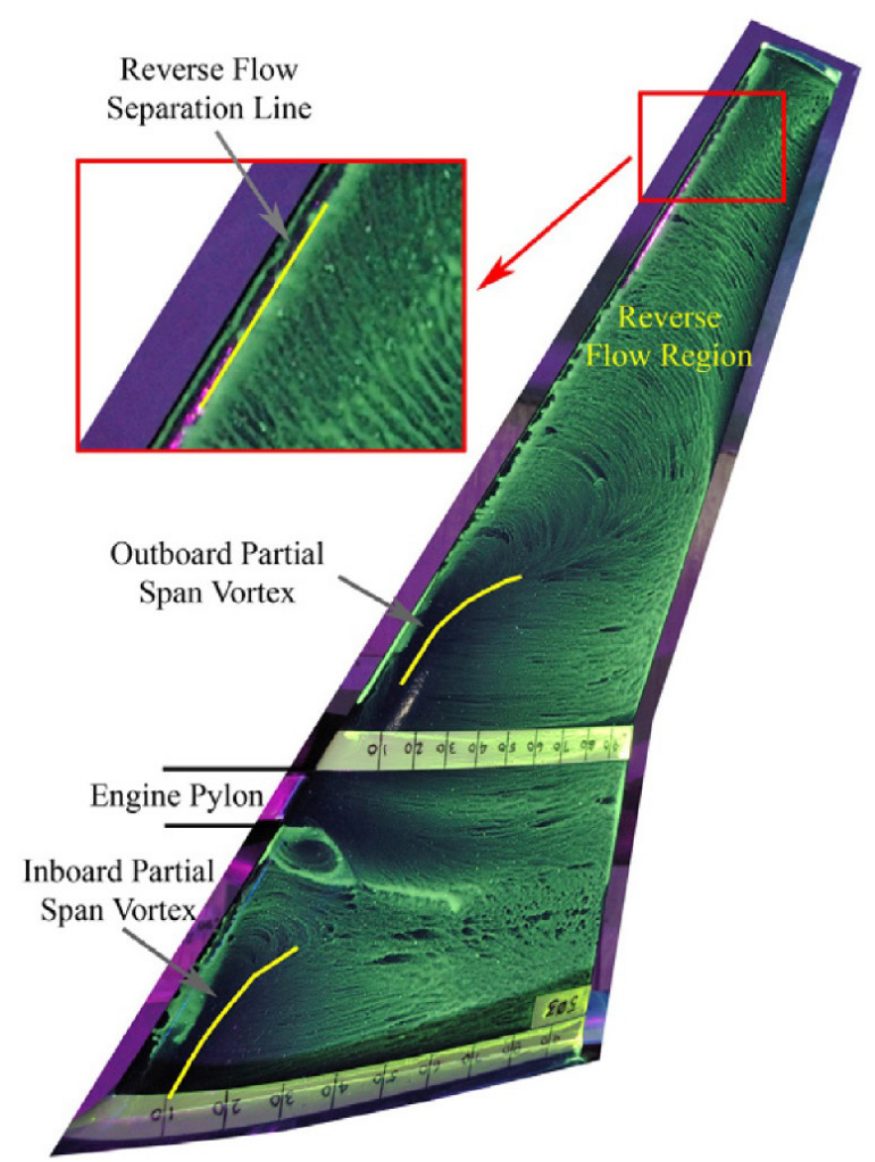

Figure 11.- Surface-oil flow visualization on the clean right wing for $\alpha=12^{\circ}$ and $\beta=0^{\circ}$ Flow is from left to right.

side of the partial-span vortex, the flow appeared to be rotating backward (in the upstream direction). This is seen most clearly on the outer 25 percent of the span where the oil flowed upstream from the trailing edge of the wing. Still visible near the leading edge is the secondary separation of the reverse flow on the outboard half of the wing. Poll (Ref. 25) also observed this flow topology for increasing angles of attack on a $30^{\circ}$ swept wing. He noted the formation of the "part-span spiral vortex" that was only capable of inducing relative weak flow at the wing surface.

Increasing the angle of attack to $14^{\circ}$ resulted in no significant changes to the surface flow topology from $12^{\circ}$. However, the partial-span vortex did appear to leave the surface of the wing farther upstream than at $12^{\circ}$. This had the effect of increasing slightly the portions of the wing with reverse surface flow. The flow between the engine-nacelle pylon and the fuselage was nearly identical to that at $\alpha=12^{\circ}$. All of the images shown in Figure 8, Figure 9 and Figure 10 were for the right wing. Flow visualization was also performed simultaneously on the left wing. No significant differences were observed. This was consistent with the roll and yaw moment data that also showed no significant asymmetries with increasing angle of attack at $\beta=0^{\circ}$.

\section{Iced Model}

The iced aerodynamics of the GTM was investigated with the artificial ice shapes installed on the wing and tail leading edges. The effect on airplane lift, drag and pitching moment coefficient is summarized in Figure 12 for $\beta=0^{\circ}$. The incremental increase in drag due to the ice shapes is clearly seen over the angle of attack range in the figure. In contrast, the lift data showed virtually no effect due to the ice shapes. In fact, there may have been a slight increase in maximum lift and stalling angle in the iced configuration. Little difference was also observed in the pitching moment.

While it appears that the effect of the artificial ice shapes on the GTM performance was minimal, this appearance was likely due to Reynolds number effects on the clean model. It is well known that the performance of two-dimensional airfoils and three-dimensional wings is influenced by Reynolds and Mach number (Refs. 26 to 28). For Mach numbers less than about 0.3 , Reynolds-number effects are usually more significant for $R e$ less than $6.0 \times 10^{6}$. As discussed later in this sections, Reynolds number effects on iced-airfoil and wing performance are much smaller in contrast to the clean configuration. Kaneshige (Ref. 29) used a combination of flight-test data and classical Reynolds number scaling techniques (Ref. 30) to estimate the high-Reynolds number lift and drag coefficients for the clean GTM. These data are also plotted in Figure 12. When comparing the estimated full-scale clean GTM data with the subscale iced-GTM data, the expected decease in maximum lift and stalling angle for the iced configuration is clearly seen. The drag penalties were also higher for incidence angles less than about $10^{\circ}$. For incidences angles of about $13^{\circ}$ and higher, the full-scale clean drag coefficient was the same or larger than for the iced configuration. This could have been due to the contribution of induced drag resulting from the higher lift coefficients for the clean configuration.

The effect of the artificial ice shapes on the lateral-directional characteristics of the 3.5 percent scale GTM are summarized in Figure 13 for angle of attack sweeps at constant sideslip and in Figure 14 for sideslip sweeps at constant angle of attack. There was little effect of the ice on rolling moment for both $\beta=0^{\circ}$ and $8^{\circ}$ in Figure 13. Still preserved is the diminished lateral stability for $\alpha>12^{\circ}$ noted by Shah et al. (Ref. 5) for the 5.5 percent scale GTM at nonzero sideslip. According to the data in Figure 13, there was an increase in yawing moment due to the artificial ice for $\beta=8^{\circ}$, perhaps due to some effect of the ice shape on the vertical stabilizer. At this sideslip angle, Shah et al. (Ref. 5) suggested that the decreasing directional stability for $\alpha>15^{\circ}$ (for both clean and iced configurations) was due to shielding of the vertical stabilizer by the fuselage. The results are further mixed for the sideslip angle sweeps for the two incidence angles shown in Figure 14. For the rolling moment, there does appear to have been a decrease in lateral stability with the iced-GTM configuration at $\alpha=14^{\circ}$. However, the yawing moment variation was mostly unaffected by the artificial ice shapes. 

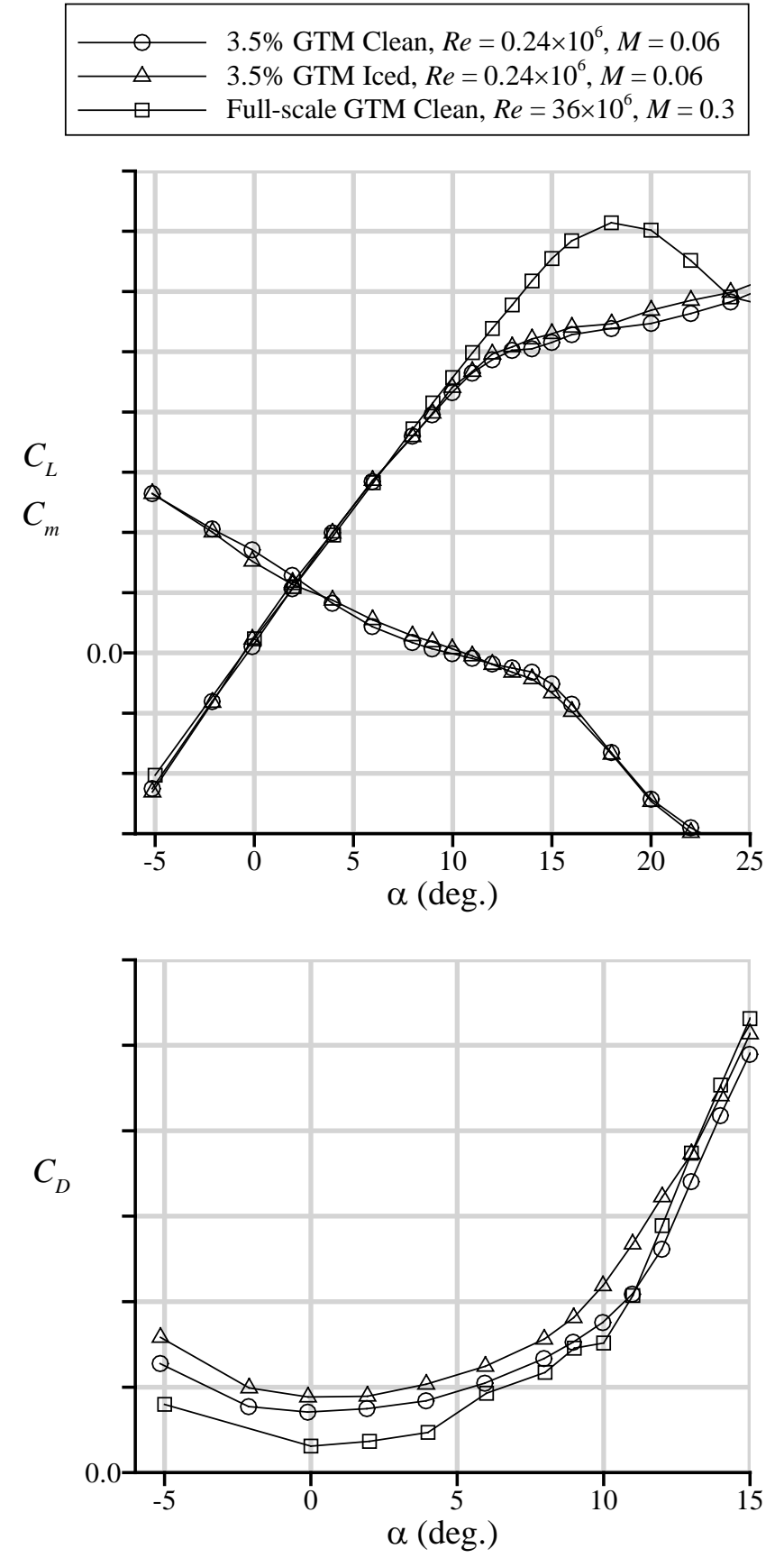

Figure 12.-Effect of artificial ice shapes on GTM longitudinal characteristics at $\beta=0^{\circ}$, Full-scale GTM data after Kaneshige (Ref. 29).
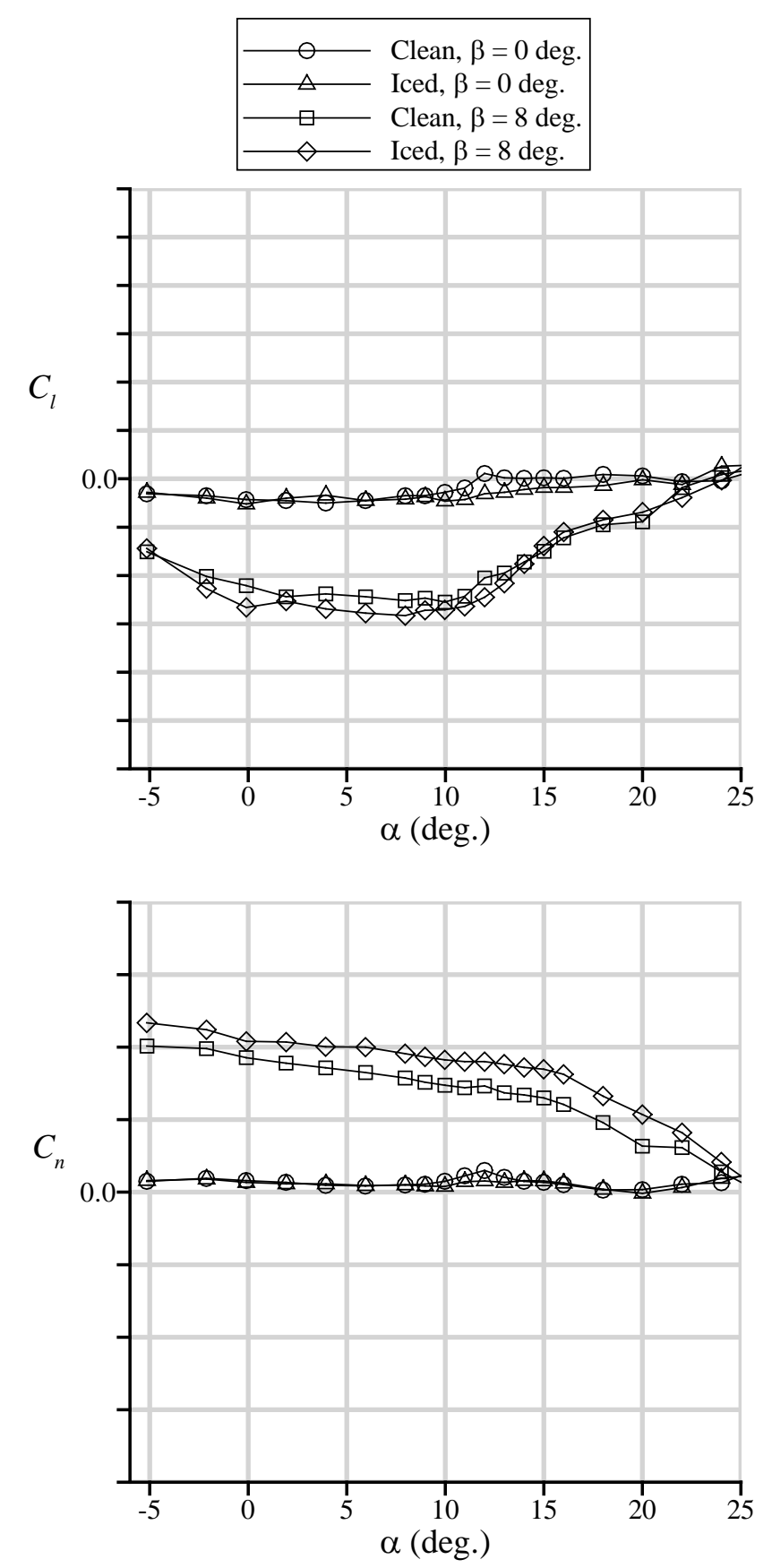

Figure 13.-Effect of artificial ice shapes on 3.5 percent scale GTM lateral-directional characteristics at fixed sideslip angle. 

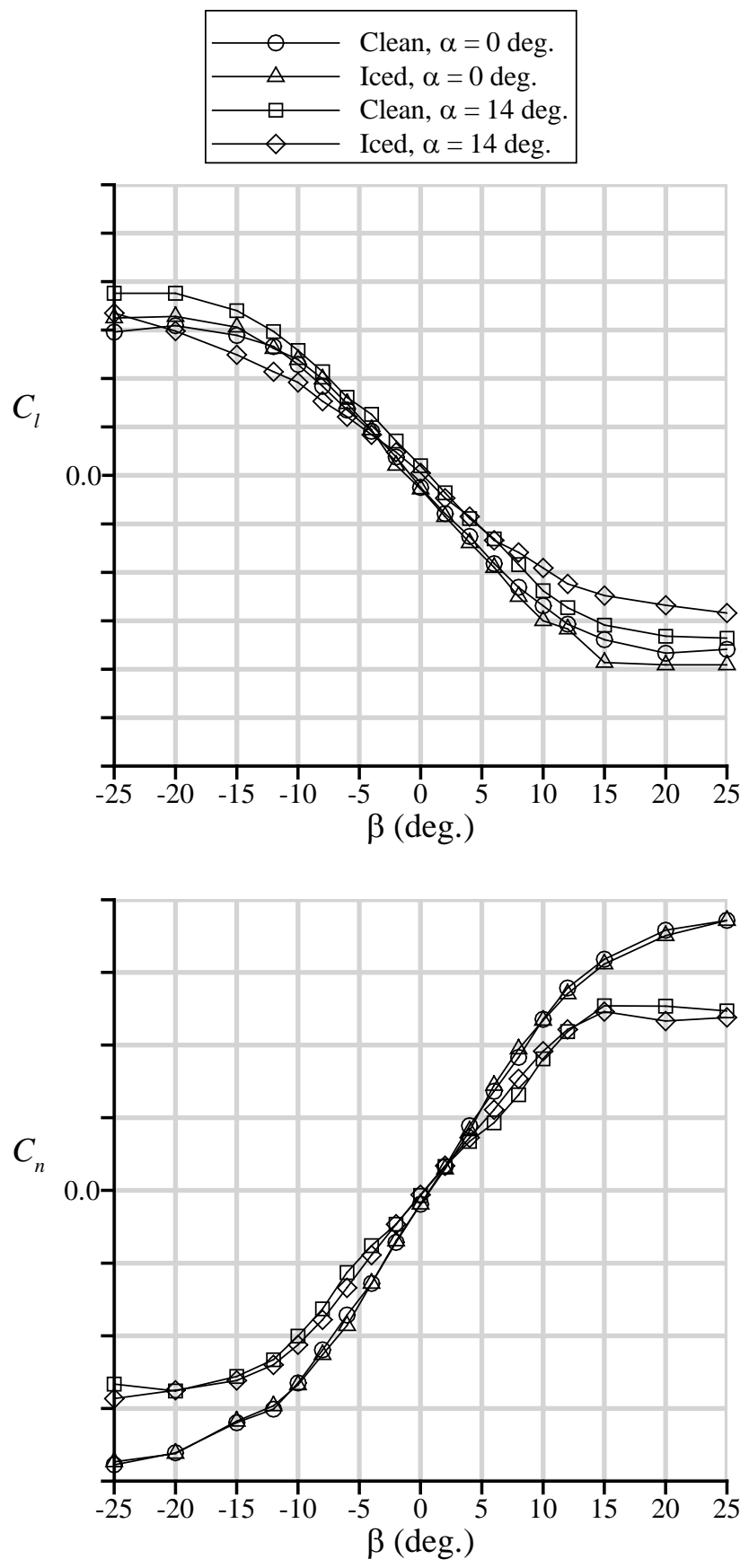

Figure 14.-Effect of artificial ice shapes on 3.5 percent scale GTM lateral-directional characteristics at fixed incidence angle.
In contrast to the clean, or un-iced, configuration, Reynolds number effects on lift and drag coefficient for airfoils, wing and airplane models with artificial ice shapes have been shown to be small. For example, Lee et al. (Ref. 17), investigated geometry and Reynolds number scaling effects on a semi-span wing panel representative of a twin-engine business jet. Aerodynamic testing was conducted with three different model scales: full scale, 42 percent scale and 8.3 percent scale over a Reynolds number range of $4.2 \times 10^{6}$ down to $0.15 \times 10^{6}$. Three different ice configurations were investigated, including a large glaze-horn similar to that used in the present work. Lee et al. (Ref. 17) found that there was very little Reynolds number dependence in the wing performance with the large glaze-horn ice shape over the range tested. In contrast, there was a large change in performance of the clean wing with Reynolds number as expected. These data are reproduced here in Figure 15 and Figure 16. The clean wing data in Figure 15 show the classic effects in the significant increase in maximum lift coefficient and stalling angle with increasing Reynolds number. For Reynolds numbers greater than $4.2 \times 10^{6}$, further increases in maximum lift and stalling angle would be expected, however, these would likely be incrementally less than those shown in the Figure 15. Typical Reynolds number effects were also seen in the pitching moment variation with angle of attack that grew more linear in the prestall region with increasing Reynolds number. This behavior is contrasted against that shown in Figure 16 for the same wing model with a large glaze-horn artificial ice shape similar to that used for the present tests. There was considerably less dependence of the performance data on Reynolds number for the iced-wing configuration. Therefore, it is reasonable to conclude that the lift and drag performance of the iced 3.5 percent scale GTM was at least representative of a full-scale condition.

The percent decrease in lift coefficient and percent increase in drag coefficient due to the artificial ice shapes was computed using the present data for the iced-GTM configuration and estimated full-scale clean performance shown in Figure 12. These increments are plotted versus angle of attack in Figure 17. In terms of lift coefficient, the effect of the ice is minimal until about $10^{\circ}$ angle of attack, while the effect on drag coefficient is largest at $\alpha=0^{\circ}$. This behavior is typical of icing flight encounters where the primary effect is reduced airspeed in cruise or holding conditions. The reduction in maximum lift coefficient and stalling angle of course become more important as more lift is required for lower airspeed conditions. Also shown in Figure 17 are analogous data for the semi-span business jet wing tested by Lee et al. (Ref. 17). In both cases, a large glaze-horn type ice shape was used in the iced-wing configuration. The data for the semi-span wing model show similar percent increases in drag, but much larger reductions in lift coefficient. (Note that the percent reduction in $C_{L}$ for $\alpha=0^{\circ}$, was large since the full-scale reference value was near 0.0.) Over 50 percent reduction in $C_{L}$ was observed for the semi-span wing compared to the 24 percent reduction in $C_{L}$ for the GTM used in the present tests. 

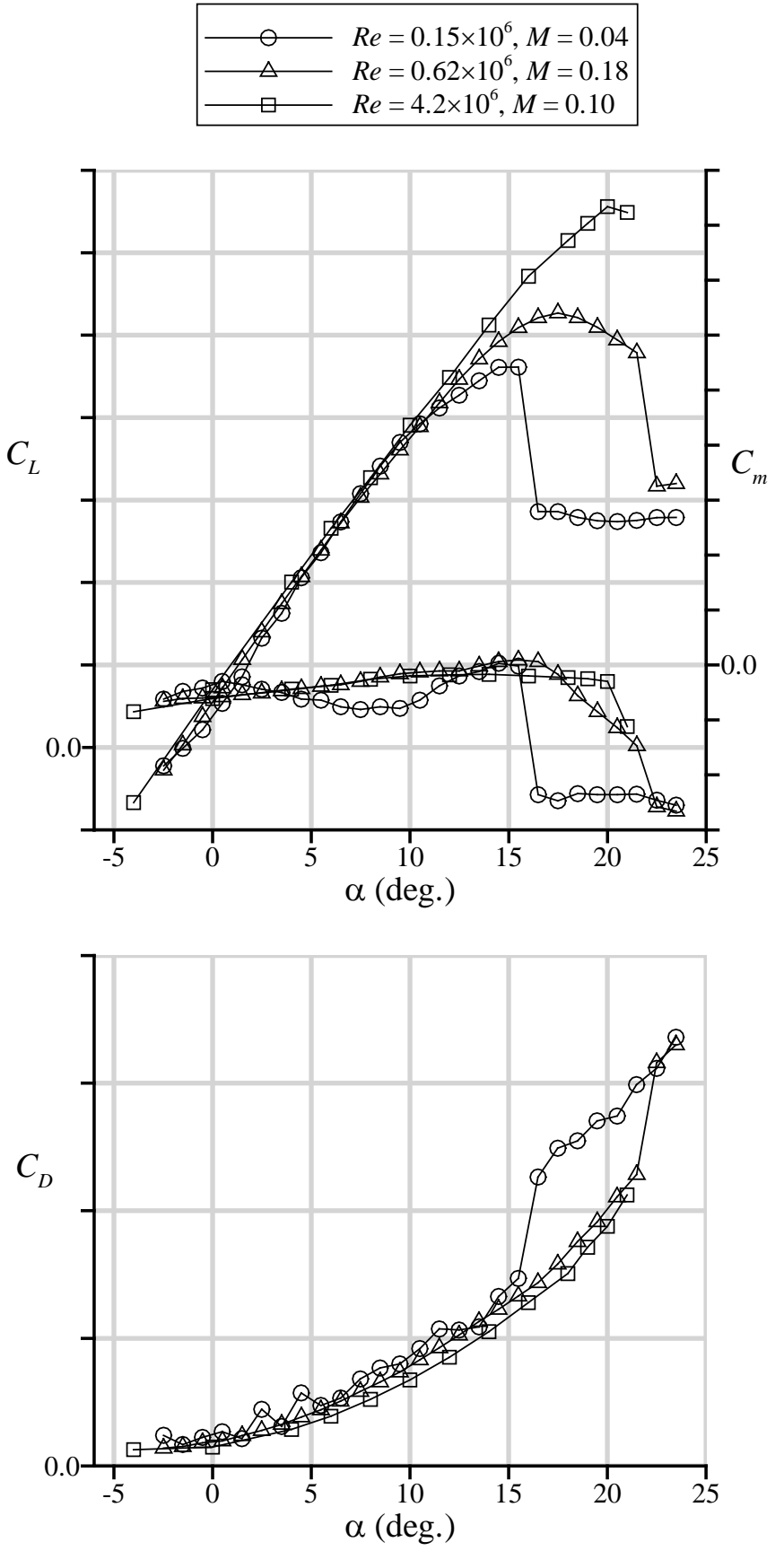

Figure 15.-Effect of Reynolds number on clean businessjet, semi-span wing model performance, after Lee et al. (Ref. 17).
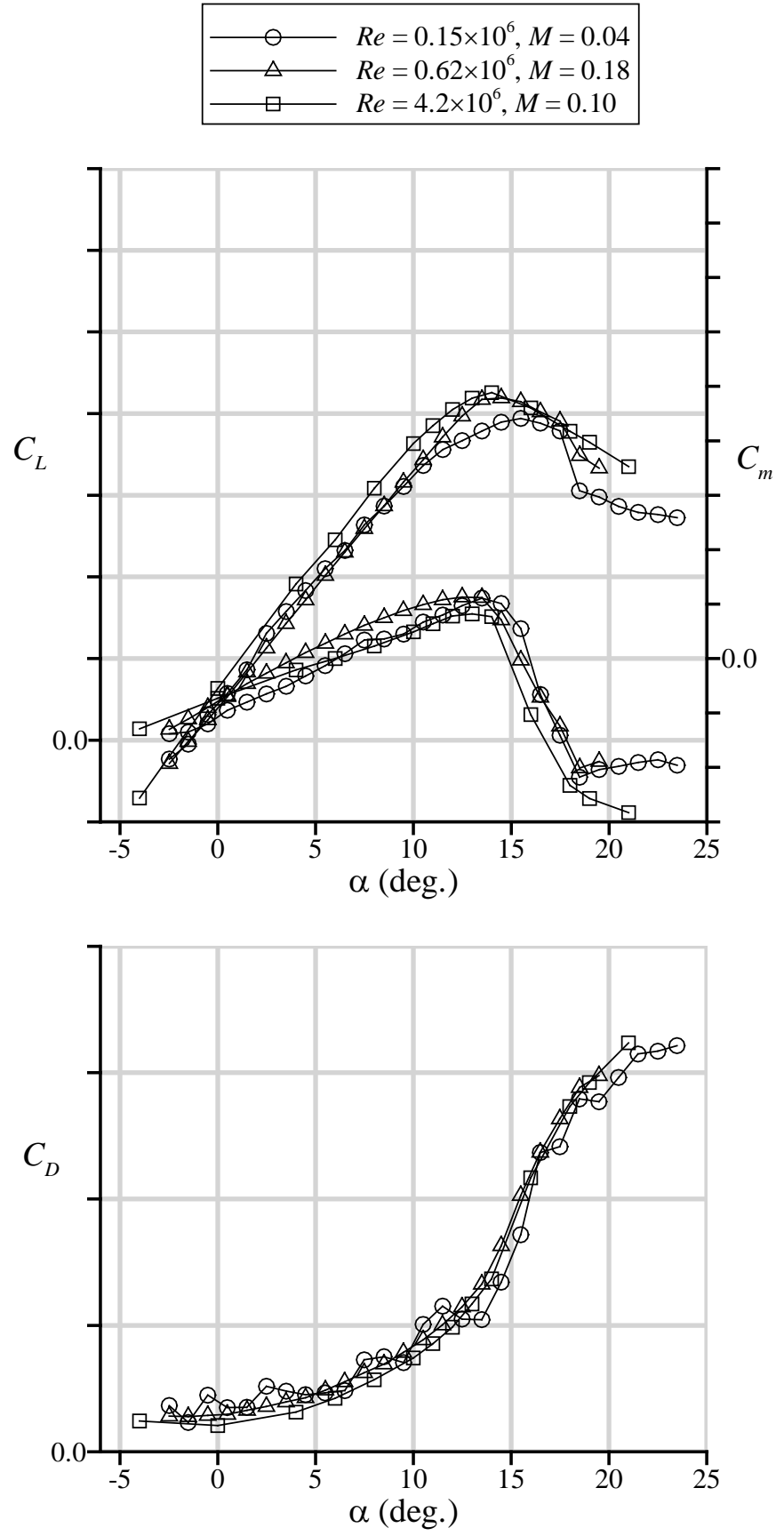

Figure 16.-Effect of Reynolds number on business-jet, semi-span wing model performance with glaze-horn artificial ice shape, after Lee et al. (Ref. 17). 

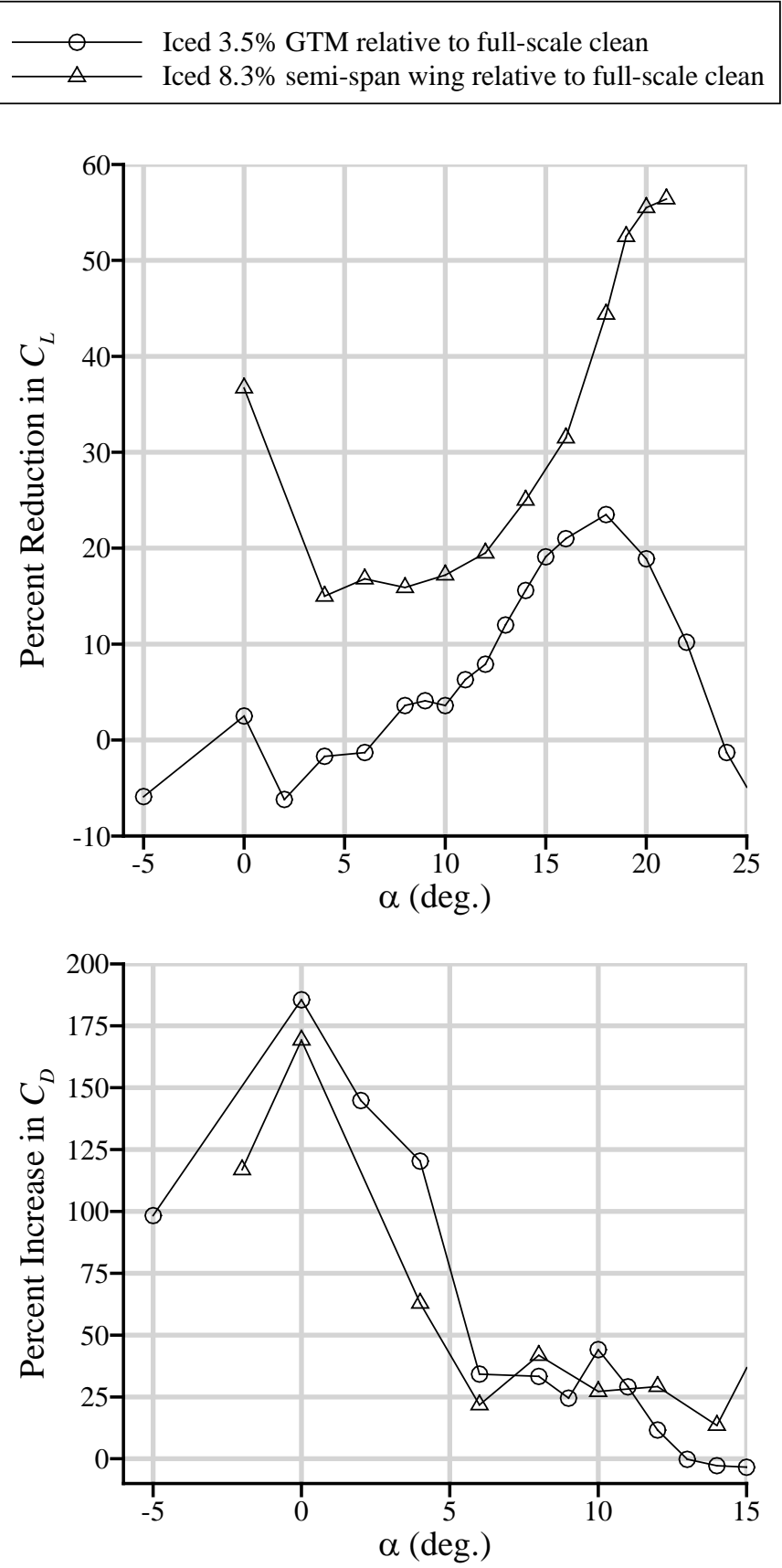

Figure 17.-Percent decrease in lift coefficient and percent increase in drag coefficient due to the artificial ice shapes on the 3.5 percent scale GTM relative to the estimated full-scale performance from Figure 12 and on the 8.3 percent scale business-jet semi span wing $\left(R e=0.15 \times 10^{6}\right)$ relative to the full-scale business jet wing $\left(R e=4.2 \times 10^{6}\right)$ from Figure 15 and Figure 16.
Comparison of the magnitude of wing/airplane lift loss is difficult because of the inherent dependencies on configuration, Reynolds number, artificial ice-shape geometry and other factors. Such factors notwithstanding, however, further comparison does yield some perspective on the present data. For example, Reehorst et al. (Ref. 31), conducted performance measurements on a 12.5 percent scale, twin-engine, short-haul transport airplane model in the NASA Langley 14- by 22-ft wind tunnel. Two full-span, leading-edge ice-shape configurations were tested, although detailed geometry information was not provided. For one configuration that appeared to be similar to the iced-GTM configuration in the present tests, the reduction in $C_{L}$ at stall was only 12 percent based upon the low-Reynolds number data. This is low relative to the values plotted in Figure 17 and was most likely due to Reynolds number effects for the clean airplane model.

Higher Reynolds number, iced-configuration data for the twin-engine, commercial transport category airplanes similar to the present GTM and that of Reehorst et al. (Ref. 31) are largely unavailable in the public domain. Lynch and Khodadoust (Ref. 32) performed a comprehensive review of iced aerodynamic performance effects. The available full-scale and/or high-Reynolds number airplane data were typically from straight-wing, propeller-driven configurations. However, Zierten and Hill (Ref. 33) reported on flight and wind-tunnel tests conducted to determine the effects of simulated ground frost on the wings of Boeing 737-200ADV, 757-200 and 767200 airplanes. For the ground frost simulations, the entire upper surfaces of the main wings were covered with appropriately sized roughness on the flight test airplanes and windtunnel models. Van Hengst et al. (Ref. 34) reproduced the maximum lift data along with data from other airplanes as shown in Figure 18. There is a wide range of maximum lift reductions from 10 to 35 percent, depending upon the airplane configuration and whether the data were from flight or windtunnel test. For the Boeing models, the flight test points and wind-tunnel data produced similar maximum lift reductions despite large differences in roughness size. Based upon these data, the 24 percent lift reduction in the present tests on the GTM (cf. Figure 17) may be on the low side, given the large size of the artificial ice shape relative to the roughness sizes shown in Figure 18. These roughness configurations may be useful for benchmarking the iced-GTM performance in any follow-on testing, provided suitable simulation methods can be implemented. An additional important distinction between the present data and that shown in Figure 18 for full-scale airplane configurations is the presence and use of the high-lift system. Such systems were not incorporated into the 3.5 percent scale GTM because the small model size and lowReynolds number would likely have negated their effectiveness. 


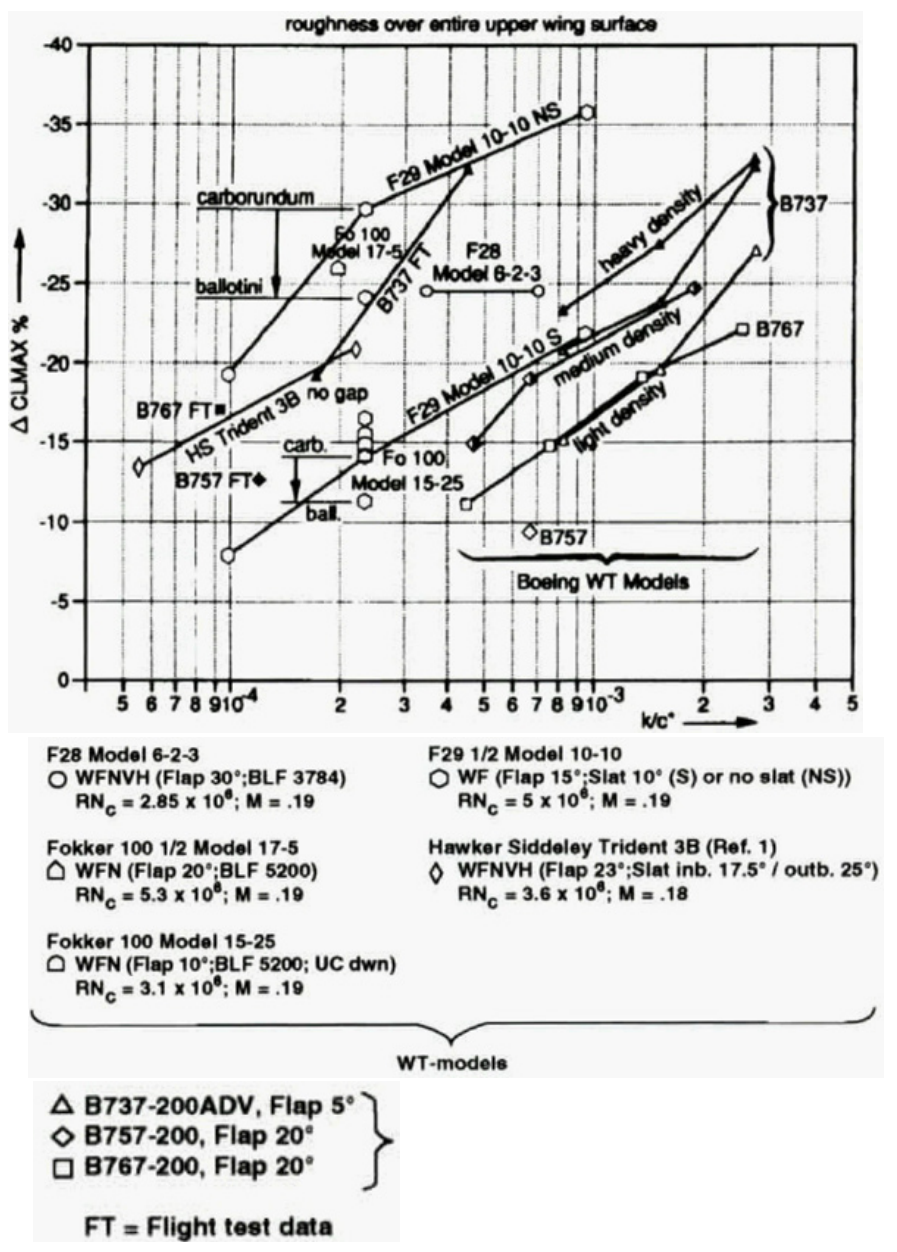

Figure 18.-Percent reductions in maximum lift coefficient for various roughness sizes and airplane configurations, after van Hengst et al. (Ref. 34) (Used with permission.)

Surface-oil flow visualization was performed on the iced configuration for $\alpha=4^{\circ}, 8^{\circ}, 10^{\circ}, 12^{\circ}$ and $14^{\circ}$ documenting the time-averaged surface flowfield on the wings leading up to stall for $\beta=0^{\circ}$. These flow visualization images were compared to those from the baseline configuration to note any significant differences due to the artificial ice shapes. For $\alpha=$ $4^{\circ}$, the ice shape caused a spanwise-running vortex to form immediately behind the ice shape. The vortex promoted surface flow to the trailing edge even near the wing tip, mitigating the low-shear/separation region observed on the clean wing (cf. Figure 8). This vortex structure was unchanged as the angle of attack was increased to $\alpha=8^{\circ}$ as illustrated in Figure 19. Similar surface-flow topology was observed comparing Figure 19 and Figure 9 for the clean model. The exception was that the approximate bubble reattachment location laid much closer to the leading edge in Figure 19 than in Figure 9. Increasing the angle of attack to $10^{\circ}$ for the iced wing caused the spanwise vortex to angle farther downstream and away from the surface in an outboard direction from the engine pylon. This was different from the clean wing

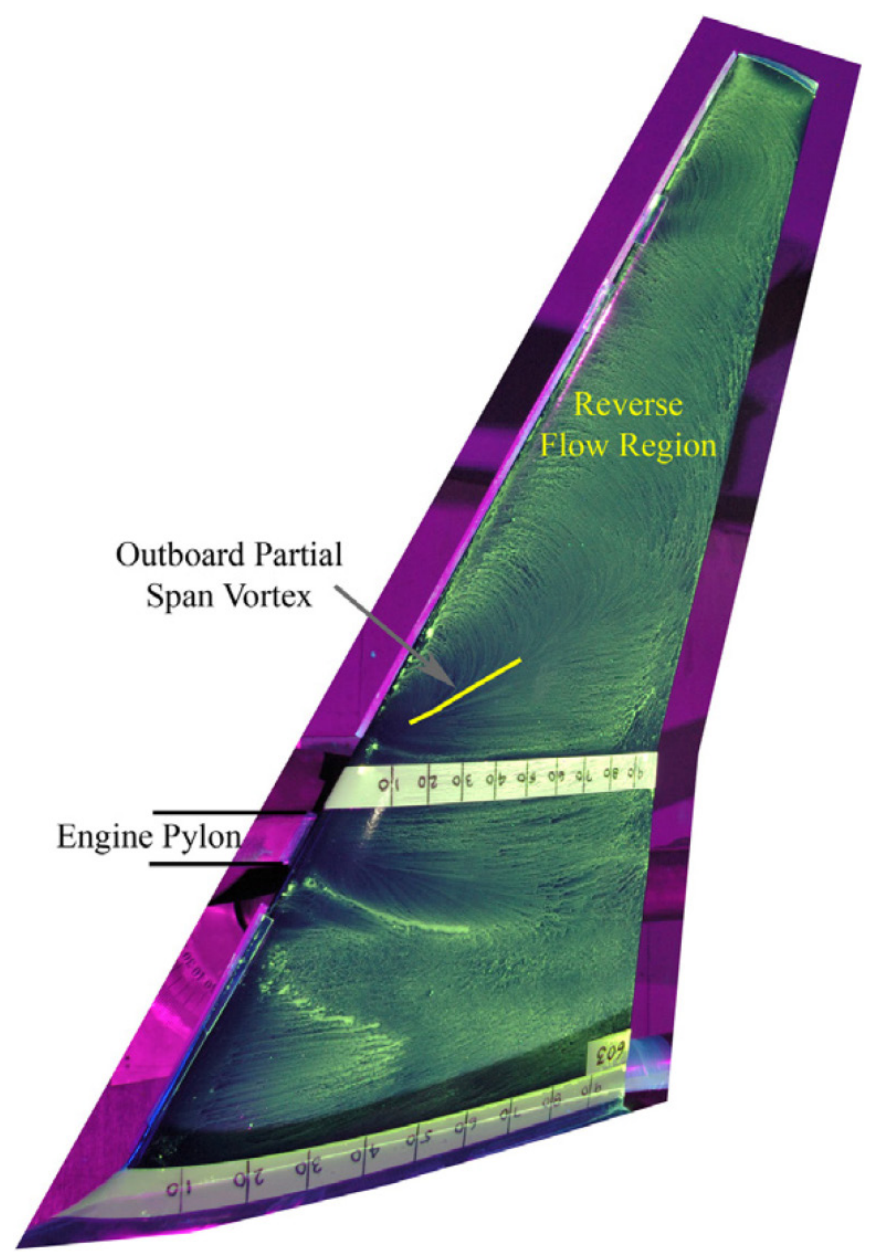

Figure 19.- Surface-oil flow visualization on the right wing with artificial ice shape for $\alpha=8^{\circ}$ and $\beta=0^{\circ}$ Flow is from left to right.

configuration where the surface flow at $\alpha=10^{\circ}$ was very similar to that at $\alpha=8^{\circ}$.

Increasing the angle of attack to $12^{\circ}$ again resulted in similar surface-flow topology between the clean and iced-wing cases. Figure 20 shows that there appeared to be two distinct flow regions, one inboard of the engine pylon and another outboard. The partial-span vortex on the inboard portion of the wing is not as visible in Figure 20 as in Figure 11, but the flow was generally in the streamwise direction toward the trailing edge. Outboard of the engine pylon, the partial-span vortex was angled toward the trailing edge as in Figure 11. The reverse flow on the outer 25 percent of the span does not appear to be as strong in the iced case (Figure 20) as for the clean case (Figure 11). The flowfields were qualitatively similar.

The evolution of the spanwise vortex associated with leading-edge ice accretion was investigated on a rectangular swept wing by Potapczuk et al. (Ref. 35) and Bragg et al. (Ref. 36) using experimental and computational methods. They noted that at low angle of attack, the spanwise vortex laid parallel to the leading edge along the reattachment location showing surface-flow topology similar to the flow on the iced-GTM 


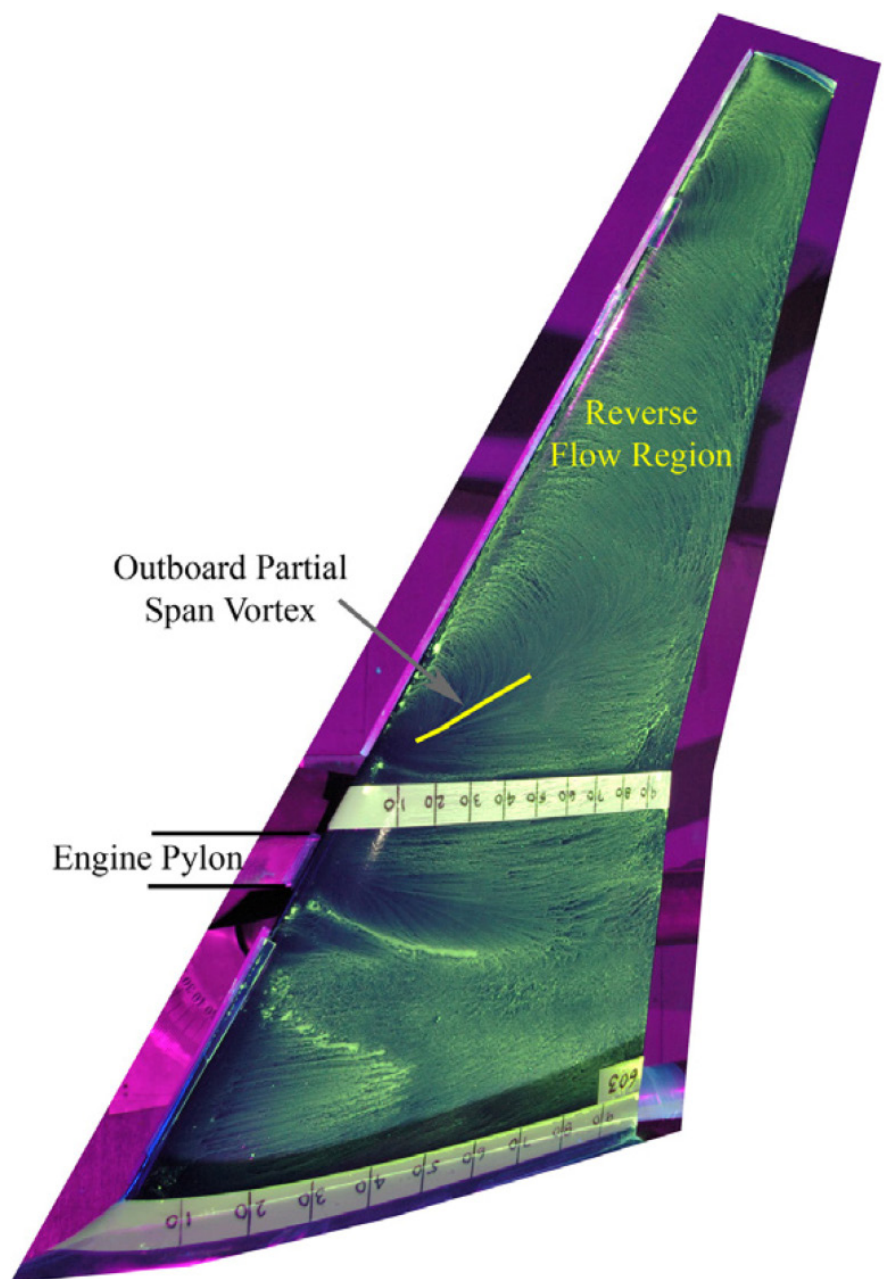

Figure 20.- Surface-oil flow visualization on the right wing with artificial ice shape for $\alpha=12^{\circ}$ and $\beta=0^{\circ}$ Flow is from left to right.

wing for $\alpha=4^{\circ}$ and $8^{\circ}$. Increasing angle of attack led to the onset of stall from the tip inboard with the spanwise vortex angling downstream and lifting off of the surface. This was similar to the observations on the iced-GTM wing for $\alpha>10^{\circ}$.

Increasing the iced GTM angle of attack to $14^{\circ}$ did not result in fundamental changes to the iced-wing flowfield. The partial-span vortex emanating from the engine pylon/wing juncture region may have angled slightly more downstream, resulting in larger extents of separated or reverse flow on the outboard portions of the wing, but this was not markedly different from that observed at $12^{\circ}$. The surface flow between the fuselage and engine pylon showed some evidence of boundary-layer separation, unlike for the clean wing. Flow visualization was simultaneously performed on the left wing and no significant differences were observed. Any minor anomalies between the right and left wings were attributable to small differences in the artificial ice-shape mounting and attachment. Overall, the flow visualization on the iced-wing configuration supported the main results from the force and moment measurements where no significant differences were observed between the clean and iced configurations.

\section{Summary and Conclusions}

An experimental research effort was begun to develop a database of airplane aerodynamic characteristics with simulated ice accretion over a large range of incidence and sideslip angles. These data are important to the development of high-fidelity flight dynamics models capable of simulating high incidence and sideslip conditions associated with airplane loss of control events. The static aerodynamic testing described in this paper represent the initial stages of the overall effort.

Wind-tunnel testing was performed at the NASA Langley 12-ft Low-Speed Wind Tunnel using a 3.5 percent scale model of the NASA Langley Generic Transport Model. Aerodynamic data were acquired from a six-component force and moment balance in static-model sweeps from $\alpha=-5^{\circ}$ to $85^{\circ}$ and $\beta=-45^{\circ}$ to $45^{\circ}$. The majority of trials were performed at a Reynolds number based on mean aerodynamic chord of $0.24 \times 10^{6}$ and Mach number of 0.06 . Surface-oil flow visualization was also performed on the main wing for selected cases and provided a qualitative understanding of the flowfield. The 3.5 percent scale GTM was tested in both the clean configuration and with full-span artificial ice shapes attached to the leading edges of the wing, horizontal and vertical tail. The artificial ice shapes were large, glaze-horn type shapes that were developed using computational ice growth analysis tools.

Aerodynamic results for the clean airplane configuration compared favorably with similar experiments carried out on a 5.5 percent scale GTM, thus yielding confidence in the model quality and wind-tunnel system. The addition of the artificial ice shapes did result in an increase in airplane drag coefficient but had little effect on the lift and pitching moment. The lateral-directional characteristics showed mixed results with a small effect of the ice shapes observed in some cases. The flow-visualization images revealed the presence and evolution of a spanwise-running vortex on the wing that was the dominant feature of the flowfield. This vortex was manifested in the leading-edge separation bubble in both the clean and iced configurations. Prior to stall, the vortex core was close to the wing surface and laid approximately parallel to the leading edge. For angles of attack near stall, two flow regimes were observed: one between the engine and fuselage and one outboard of the engine. In the latter regime, the spanwise vortex angled downstream and off the surface resulting in separated and reverse flow on the outboard portion of the wing. This occurred in both configurations, thus supporting the comparisons in the force and moment data.

The lack of ice-induced performance and flowfield effects observed in this effort was likely due to Reynolds number effects for the clean configuration. Based upon observations taken from other work, it is likely that the iced-airplane data 
acquired here represents a reasonable simulation of the fullscale behavior. Estimates of full-scale baseline performance were included in this analysis to illustrate the potential icing effects. However, these estimates are limited. A better understanding of the full-scale, high-Reynolds number GTM aerodynamics is needed in order to fully evaluate the potential icing effects.

\section{References}

1. Totah, J., Krishnakumar, K., and Viken, S., "Integrated Resilient Aircraft Control-Stability, Maneuverability and Safe Landing in the Presence of Adverse Conditions," NASA Aviation Safety Program Technical Plan, Apr. 2007.

2. Reehorst, A.L., Addy, H.E., Jr., Colantonio, R.O., "Examination of Icing Induced Loss of Control and Its Mitigations,” AIAA Paper 2010-8140, Aug. 2010.

3. Ratvasky, T.P. and Lee, S., "Current Knowledge of Icing Effects on Aircraft Control,” NASA White Paper, Dec. 2007.

4. Foster, J.V., Cunningham, K., Fremaux, C.M., Shah, G.H., Stewart, E.C., Rivers, R.A., Wilborn, J.E., and Gato, W., "Dynamics Modeling and Simulation of Large Transport Airplanes in Upset Conditions,” AIAA Paper 2005-5933, Aug. 2005.

5. Shah, G.H., Cunningham, K., Foster, J.V., Fremaux, C.M., Stewart, E.C., Wilborn, J.E., Gato, W and Pratt, D.W., "Wind Tunnel Investigation of Commercial Transport Aircraft Aerodynamics at Extreme Flight Conditions,” SAE-2002-01-2912, Nov. 2002.

6. Shah, G.H., "Aerodynamic Effects and Modeling of Damage to Transport Aircraft,” AIAA Paper 2008-6203, Aug. 2008.

7. Murch, A.M., and Foster, J.V., "Recent NASA Research on Aerodynamic Modeling of Post-Stall and Spin Dynamics of Large Transport Airplanes,” AIAA Paper 20070463, Jan. 2007.

8. Owens, D.B., Brandon, J.M., Croom, M.A., Fremaux, C.M., Heim, E.H., and Vicroy, D.D., "Overview of Dynamic Test Techniques for Flight Dynamics Research as NASA LaRC,” AIAA Paper 2006-3146, Jun. 2006.

9. Frink, N.T., Pirzadeh, S.Z., Atkins, H.L., Viken, S.A., and Morrison, J.H., "CFD Assessment of Aerodynamic Degradation of a Subsonic Transport Due to Airframe Damage.” AIAA Paper 2010-0500, Jan. 2010.

10. Ratvasky, T.P., Ranaudo, R.J., Barnhart, B.P., Dickes, E.G., and Gingras, D.R., "Development and Utility of a Piloted Flight Simulator for Icing Effects Training," AIAA Paper 2003-0022, Jan. 2003, also NASA/TM2003-212116, Apr. 2003.

11. Papadakis, M., Gile-Laflin, B.E., Youssef, G.M., and Ratvasky, T.P., "Aerodynamic Scaling Experiments with Simulated Ice Accretions,” AIAA Paper 2001-0833, Jan. 2001.
12. Gingras, D.R., Dickes, E.G., Ratvasky, T.P., and Barnhart, B.P., "Modeling of In-Flight Icing Effects for Pilot Training,” AIAA Paper 2002-4605, Aug. 2002.

13. Ratvasky, T.P., Ranaudo, R.J., Blankenship, K.S., and Lee, S., "Demonstration of an Ice Contamination Effects Flight Training Device,” AIAA 2006-0677, Jan. 2006, also NASA/TM-2006-214233, May 2006.

14. Gingras, D.R., Barnhart, B., Ranaudo, R., Martos, B., Ratvasky, T.P., and Morelli, E., "Development and Implementation of a Model-Driven Envelope Protection System for In-Flight Ice Contamination,” AIAA Paper 2010-8141, Aug. 2010.

15. Ranaudo, R., Martos, B., Norton, B., Gingras, D.R., Barnhart, B., Ratvasky, T.P., and Morelli, E., "Piloted Simulation to Evaluate the Utility of a Real-Time Envelope Protection System for Mitigating In-Flight Icing Hazards,” AIAA Paper 2010-7987, Aug. 2010.

16. Gingras, D.R., Barnhart, B., Ranaudo, R., Ratvasky, T.P., and Morelli, E., "Envelope Protection for In-Flight Ice Contamination,” AIAA Paper 2009-1458, Jan. 2009.

17. Lee, S., Ratvasky, T.P., Thacker, M., and Barnhart, B.P., "Geometry and Reynolds Number Scaling Experiments with Simulated Ice Accretions,” AIAA Paper 2005-1066, Jan. 2005, also NASA/TM-2005-213575, Aug. 2005.

18. Lee, S., Barnhart, B.P., Ratvasky, T.P., and Thacker, M., "Dynamic Wind-Tunnel Testing of a Sub-scale Iced Business Jet,” AIAA Paper 2006-0261, Jan. 2006, also NASA/TM-2006-214268, May 2006.

19. Ratvasky, T.P., Barnhart. B.P., Lee, S., and Cooper, J., "Flight Testing an Iced Business Jet for Flight Simulation Model Validation,” AIAA Paper 2007-0089, Jan. 2007, also NASA/TM-2007-214936, Dec. 2007.

20. Ratvasky, T.P., Barnhart, B.P., and Lee, S., "Current Methods Modeling and Simulating Icing Effects on Aircraft Performance, Stability, Control.” Journal of Aircraft, Vol. 47, No. 1, Jan.-Feb., 2010, pp. 201-211, also AIAA Paper 2008-6204, Aug. 2008.

21. Kline, S., and McClintock, F.A, "Describing Uncertainties in Single Sample Experiments,” Mechanical Engineering, Vol. 75, No. 1, 1953, pp. 3-8.

22. Coleman, H.W., and Steele, W.G., Experimentation and Uncertainty Analysis for Engineers, Wiley-Interscience, New York, 1989.

23. Wright, W.B., “User’s Manual for LEWICE Version 3.2,” NASA/CR-2008-214255, Nov. 2008.

24. Bidwell, C.S., Pinella, D., and Garrison, P., "Ice Accretion Calculations for a Commercial Transport Using the LEWICE3D, ICEGRID3D and CMARC Programs," NASA/TM-1999-208895, Jan. 1999.

25. Poll, D.I.A., "Spiral Vortex Flow Over a Swept-back Wing,” Aeronautical Journal, May 1986, pp. 185-199.

26. Abbott, I.H., and Von Doenhoff, A.E., Theory of Wing Sections, Dover, New York, NY, 1959. 
27. Polhamus, E.C., "A Survey of Reynolds Number and Wing Geometry Effects on Lift Characteristics in the Low-Speed Stall Region,” NASA CR-4745, Jun. 1996.

28. Furlong, G.C., and McHugh, J.G., "A Summary and Analysis of the Low-Speed Longitudinal Characteristics of Swept Wings at High Reynolds Number," NACA TR1339, 1952.

29. Kaneshige, J., "Development of a Full-Scale Generic Transport Model (GTM) Simulation,” Private Communication, Sept. 21, 2010.

30. Rae, W.H., Jr., and Pope, A., Low-Speed Wind Tunnel Testing, $2^{\text {nd }}$ Ed., John Wiley \& Sons, New York, NY, 1984.

31. Reehorst, A., Potapczuk, M., Ratvasky, T., and Laflin, B.G., "Wind-Tunnel Measured Effects on a Twin-Engine Short-Haul Transport Caused by Simulated Ice Accretions,” AIAA Paper 96-0871, Jan. 1996, also NASA TM107143, Jan. 1996, see also Data Report, NASA TM107419, May 1997.

32. Lynch, F.T., and Khodadoust, A., "Effects of Ice Accretion on Aircraft Aerodynamics," Progress in Aerospace Sciences, Vol. 37, No. 8, Nov. 2001, pp. 669-767.
33. Zierten, T.A., and Hill, E.G., "Effects of Wing Simulated Ground Frost on Airplane Performance" in Influence of Environmental Factors on Aircraft Wing Performance, von Karman Institute for Fluid Dynamics, Lecture Series 1987-03, Feb. 1987.

34. Van Hengst, J., Gent, R., Hammond, D., Seubert, R., and Wagner, B., "Ice Accretion and Its Effects on Aircraft," in Ice Accretion Simulation, AGARD AR-344, Paper 3, Dec. 1997.

35. Potapczuk, M.G., Bragg, M.B., Kwon, O.J., and Sankar, L.N., "Simulation of Iced Wing Aerodynamics," in Effects of Adverse Weather on Aerodynamics, AGARD CP496, Paper 7, Dec. 1991. Also NASA TM-104362, May 1991.

36. Bragg, M.B., Kerho, M.F., and Khodadoust, A., "LDV Flowfield Measurements on a Straight and Swept Wing with a Simulated Ice Accretion,” AIAA Paper 93-0300, Jan. 1993. 


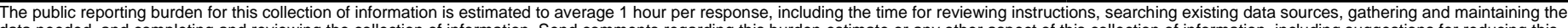

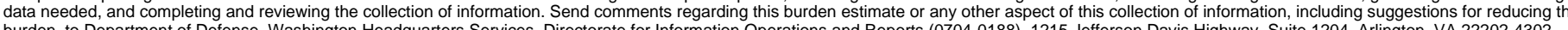
burden, to Department of Defense, Washington Headquarters Services, Directorate for Information Operations and Reports (0704-0188), 1215 Jefferson Davis Highway, Suite 1204, Arlington, VA 22202-4302.

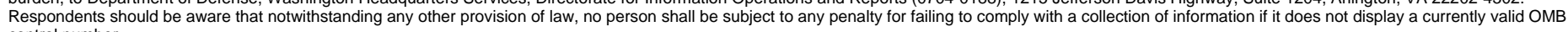

COntrol number.

\begin{tabular}{l|l|l}
\hline 1. REPORT DATE (DD-MM- $Y Y Y Y)$ & 2. REPORT TYPE & 3. DATES COVERED (FrOm - TO)
\end{tabular}

\begin{tabular}{l|l}
$01-02-2012$ & Technical Memorandum
\end{tabular}

4. TITLE AND SUBTITLE

Aerodynamic Effects of Simulated Ice Accretion on a Generic Transport Model

5a. CONTRACT NUMBER

5b. GRANT NUMBER

5c. PROGRAM ELEMENT NUMBER

5d. PROJECT NUMBER

Broeren, Andy, P.; Lee, Sam; Shah, Gautam, H.; Murphy, Patrick, C.

5e. TASK NUMBER

5f. WORK UNIT NUMBER

WBS 457280.02.07.03.02.02

7. PERFORMING ORGANIZATION NAME(S) AND ADDRESS(ES)

National Aeronautics and Space Administration

John H. Glenn Research Center at Lewis Field

8. PERFORMING ORGANIZATION

REPORT NUMBER

E-18002

Cleveland, Ohio 44135-3191

9. SPONSORING/MONITORING AGENCY NAME(S) AND ADDRESS(ES)

National Aeronautics and Space Administration

Washington, DC 20546-0001

\section{SPONSORING/MONITOR'S ACRONYM(S) \\ NASA}

11. SPONSORING/MONITORING

REPORT NUMBER

NASA/TM-2012-217246

\section{DISTRIBUTIONIAVAILABILITY STATEMENT}

Unclassified-Unlimited

Subject Categories: 01, 02, and 03

Available electronically at http://www.sti.nasa.gov

This publication is available from the NASA Center for AeroSpace Information, 443-757-5802

\section{SUPPLEMENTARY NOTES}

\section{ABSTRACT}

An experimental research effort was begun to develop a database of airplane aerodynamic characteristics with simulated ice accretion over a large range of incidence and sideslip angles. Wind-tunnel testing was performed at the NASA Langley 12-ft Low-Speed Wind Tunnel using a 3.5 percent scale model of the NASA Langley Generic Transport Model. Aerodynamic data were acquired from a six-component force and moment balance in static-model sweeps from $\alpha=-5^{\circ}$ to $85^{\circ}$ and $\beta=-45^{\circ}$ to $45^{\circ}$ at a Reynolds number of $0.24 \times 106$ and Mach number of 0.06. The 3.5 percent scale GTM was tested in both the clean configuration and with full-span artificial ice shapes attached to the leading edges of the wing, horizontal and vertical tail. Aerodynamic results for the clean airplane configuration compared favorably with similar experiments carried out on a 5.5 percent scale GTM. The addition of the large, glaze-horn type ice shapes did result in an increase in airplane drag coefficient but had little effect on the lift and pitching moment. The lateral-directional characteristics showed mixed results with a small effect of the ice shapes observed in some cases. The flow visualization images revealed the presence and evolution of a spanwise-running vortex on the wing that was the dominant feature of the flowfield for both clean and iced configurations. The lack of iceinduced performance and flowfield effects observed in this effort was likely due to Reynolds number effects for the clean configuration. Estimates of full-scale baseline performance were included in this analysis to illustrate the potential icing effects.

15. SUBJECT TERMS

Aircraft icing; Aircraft performance; Aerodynamic characteristics

\begin{tabular}{|c|c|c|c|c|c|}
\hline \multicolumn{3}{|c|}{ 16. SECURITY CLASSIFICATION OF: } & \multirow{2}{*}{$\begin{array}{l}\text { 17. LIMITATION OF } \\
\text { ABSTRACT } \\
\text { UU }\end{array}$} & \multirow{2}{*}{$\begin{array}{l}\text { 18. NUMBER } \\
\text { OF } \\
\text { PAGES } \\
24\end{array}$} & \multirow{2}{*}{$\begin{array}{l}\text { 19a. NAME OF RESPONSIBLE PERSON } \\
\text { STI Help Desk (email:help@sti.nasa.gov) } \\
\text { 19b. TELEPHONE NUMBER (include area code) } \\
\text { 443-757-5802 }\end{array}$} \\
\hline $\begin{array}{l}\text { a. REPORT } \\
U\end{array}$ & $\begin{array}{l}\text { b. ABSTRACT } \\
U\end{array}$ & $\begin{array}{l}\text { c. THIS } \\
\text { PAGE } \\
\text { U }\end{array}$ & & & \\
\hline
\end{tabular}



